\title{
LOS CENTROS HISTÓRICOS DE TOLEDO Y CUENCA. NUEVOS EQUIPAMIENTOS SOCIOCULTURALES PARA LA RECUPERACIÓN FUNCIONAL ${ }^{1}$.
}

\author{
Ana Eulalia APARICIO GUERRERO \\ Facultad de CC.EE. y Humanidades. Cuenca. UCLM. \\ Ana.Aparicio@uclm.es
}

Recibido: $14 / 10 / 2013$

Aceptado: 01/03/2014

RESUMEN: Si bien el proyecto de investigación en el que se inserta nuestro estudio aborda el fenómeno de la renovación y revitalización de los centros históricos desde la escala nacional a la local, en el presente trabajo nos centraremos en los centros históricos de las dos ciudades Patrimonio de la Humanidad de Castilla-La Mancha y más concretamente en dos equipamientos socioculturales.

El estudio se divide en dos partes. En la primera se incide en la política urbana diseñada a escala regional por la Consejería de Educación y Cultura de la Junta de Comunidades de Castilla-La Mancha con el fin de revitalizar estos espacios, y en el planeamiento especial en dos estudios de caso a escala macro, el Centro Histórico de Cuenca y el Centro Histórico de Toledo. En la segunda, más práctica, se comienza con el análisis de dos proyectos urbanos de nueva planta asociados a usos socioculturales, dos estudios de caso a escala micro, la construcción del Teatro-Auditorio de Cuenca realizado por José María García de Paredes y del Palacio de Congresos de Toledo "El Greco" del arquitecto y Premio Príncipe de Asturias Rafael Moneo, y se termina con la evaluación de la información conseguida en las entrevistas realizadas a distintos agentes urbanos relacionados con estos espacios. Posteriormente se desarrolla el debate, la fase propositiva y las conclusiones finales de la investigación.

PALABRAS CLAVE: Centros históricos, equipamiento sociocultural, recuperación funcional, coordinación, gobernanza, sostenibilidad.

THE HISTORICAL CENTERS OF TOLEDO AND CUENCA. NEW SOCIOCULTURAL FACILITIES FOR THE SOCIOCULTURAL RECOVERY.

ABSTRACT: While the research project in which our study is inserted addresses the phenomenon of renewal and revitalization from the national to the local scale, in this paper we will

1 El presente texto se incardina en el proyecto de investigación Las ciudades españolas en la etapa autonómica (1978-2012). Dinámicas, procesos y políticas (URBSPAIN), financiado por el Plan Nacional de Investigación I+D+i del Ministerio de Economía y Competitividad para el período 2010-2013 (Código CSO 2009-11261-Subpr. GEOG). 
focus on the historical centers of the two World Heritage cities of Castilla-La Mancha and more specifically on two sociocultural facilities.

The research is divided into two independent parts. The first, of basic investigation, deals with the urban policy designed at a regional level by the Counseling of Education and Culture of the Community Board from Castilla-La Mancha in order to revitalize these spaces, and in the special planning at a local level in two cases of study on a broad scale, the historic center of Cuenca and the Historic Center of Toledo. In the second, more practical, we start with the analysis of two urban projects of new plant, associated with socio-cultural uses, two studies of cases of micro-scale: the construction of the Theatre - Auditorium of Cuenca made by José María García de Paredes and the Palace of Congress "El Greco" in Toledo by the architect and Prince of Asturias Award Rafael Moneo, and it ends with the evaluation of the information gathered in interviews to various urban agents related to these areas. Then, the discussion, the propositional phase and the final conclusions of the research are developed.

KEYWORDS: historical centers, cultural facilities, functional recovery, coordination, governance, sustainability.

Los centros históricos han conocido a lo largo del tiempo cambios significativos en su estructura funcional para adaptarse a las diferentes coyunturas históricas y demandas de los grupos sociales que los han habitado o utilizado. A partir de mediados del siglo XIX y especialmente en el XX los cambios son mucho más radicales; la ciudad histórica irá perdiendo buena parte de las funciones centrales, y tras unos años de despoblación, pérdida de vitalidad funcional y deterioro físico, a partir de los años ochenta se iniciará una fase de cierta recuperación urbana, donde múltiples iniciativas, públicas y privadas, buscan adaptar la ciudad a las necesidades de la sociedad, conservando funciones de origen preindustrial, e incorporando otras nuevas relacionadas con el carácter simbólico, cultural, turístico o lúdico que iba adquiriendo (Troitiño, 1998; CAmpos, 1999).

Las políticas de renovación y de rehabilitación, así como el planeamiento urbano son los instrumentos utilizados por la administración para mejorar los distintos centros históricos, y volver a hacer de estos lugares espacios habitables, funcionales, con nuevas funciones y actividades y adaptados a la vida moderna (SANTAMARía, 2013). Las comunidades autónomas han hecho un importante esfuerzo para configurar políticas orientadas, en mayor o menor medida, a proteger, renovar, recuperar o revitalizar los centros históricos de nuestras ciudades. Durante estos años ha tenido lugar un interesante proceso de formulación e instrumentalización de políticas urbanas y de planeamiento especial, orientados, en mayor o menor medida, a proteger, renovar, recuperar o revitalizar los centros históricos de nuestras ciudades. Como consecuencia de la aplicación de estas políticas y de la entrada en vigor de estos planes especiales se ha conseguido 
una importante recuperación física del patrimonio monumental y considerables cambios funcionales.

Los proyectos ejecutados han dado un impulso importante a la recuperación de la ciudad e introducido cambios funcionales y sociales de signo diverso, pero la inexitencia de infraestructuras de gestión capaces de afrontar la recuperación integrada hizo muy difícil la consecución de unos resultados totalmente satisfactorios. La gestión de un centro histórico debe ir más allá de la mera regulación urbanística o arquitectónica, incorporando plenamente los aspectos funcionales y apostando por estrategias de multifuncionalidad donde colaboren las administraciones públicas, los agentes económicos privados, la iglesia y la población residente.

Especialmente de gran interés para la revitalización y la multifuncionalidad de estos espacios resulta la consideración del turismo cultural. En la actualidad la combinación de turismo y cultura resulta necesaria para el desarrollo económico de ciertas áreas urbanas, posibilitando tanto la generación de empleo como la vertebración de los ingresos necesarios para la conservación y para la recuperación del patrimonio histórico-cultural. El modelo económico existente en España ha convertido la cultura en una vertiente de la economía, percibiéndose las actividades artísticas como un capítulo específico dentro de los ingresos turísticos. En este sentido, el refuerzo de las funciones culturales y lúdicas puede contribuir, si no adquieren carácter excluyente, a enriquecer la vida de estos espacios y a reforzar su utilización colectiva. El turismo constituye un pilar importante de la economía de muchas ciudades históricas, habiendo contribuido también a la puesta en marcha de procesos de revitalización económica.

Según la tipología urbana de los municipios turísticos realizada por Precedo y Mínguez (2007), la ciudades históricas de Toledo y Cuenca se han incorporado activamente, y en este orden, a los flujos del turismo cultural. Aunque cataloga a Toledo como ciudad más especializada, ambas poseen una importante especialización turística, sobre todo si comparamos el peso de estas actividades en la economía urbana local y lo relacionamos con el tamaño de la ciudad. La revitalización de los centros históricos implica mantenerlos vivos, impulsar la vivienda y las actividades compatibles, culturales y de servicios. A las actuaciones de rehabilitación de viviendas y de locales comerciales, de mejora de infraestructuras y equipamiento, de mejora de la escena urbana y de rehabilitación y cambio de uso de viejos edificios, se debería añadir otro factor importante a la hora de diseñar una estrategia de revitalización de los centros históricos: la inserción de nuevas edificaciones, la construcción de nuevos equipamientos para fines socioculturales. El desafío al que se enfrentan actualmente los centros históricos y el 
patrimonio cultural urbano en general, no es sólo el de su conservación sino el de la incorporación y articulación de la nueva arquitectura en los tejidos urbanos tradicionales, de "los procesos de creación-producción contemporánea", a fin de satisfacer las necesidades vivas de la sociedad (GonzÁlez, 1991, De la CALLE, 2013a: 82), porque las ciudades históricas son "lugares donde la mayor parte de la afluencia de visitantes está motivada por el atractivo de su entramado cultural", una cultura que incluye "tanto manifestaciones del patrimonio como de la creación y recreación cultural contemporánea" (DE LA CALLE, 2013b: 232). En definitiva, la arquitectura de hoy, las infraestructuras o equipamientos culturales donde se desarrollan actividades relacionadas con el ejercicio de las artes -teatros, auditorios, salas de concierto, etc.- es uno de los instrumentos para la revitalización y puesta en valor de los asentamientos antiguos.

\section{OBJETIVOS, PLANTEAMIENTO Y METODOLOGÍA.}

Aunque el proyecto de investigación en el que se inserta nuestro estudio aborda el período de tiempo comprendido entre la promulgación de la constitución Española en 1978 y la actualidad, en nuestro trabajo se considerará la instauración del Estado de las Autonomías como el inicio de nuestra labor investigadora, momento a partir del cual las distintas regiones españolas van adquiriendo las competencias que la Constitución les otorgaba en materia de urbanismo y ordenación del territorio, y empiezan a legislar sobre el tema.

En la fase inicial del proyecto nos centramos en un análisis de la normativa regional en materia de urbanismo y ordenación del territorio y los criterios de sostenibilidad urbana que éstas recogen en sus textos. Posteriormente pasamos a realizar un estudio sobre el papel que el establecimiento de la capitalidad regional ha supuesto en los centros históricos en cuanto a la potenciación de las políticas y actuaciones urbanas dirigidas a la rehabilitación y reutilización del patrimonio urbano al servicio de esas funciones de capitalidad autonómica, abordando un análisis comparado entre la Comunidad Foral de Navarra y la Comunidad de Castilla-La Mancha, entre Pamplona y Toledo. En la tercera fase del proyecto nos centramos en la región castellano-manchega y en sus dos ciudades Patrimonio de la Humanidad: Toledo y Cuenca, en el planeamiento general, en la planificación especial y en las políticas urbanas puestas en marcha por la Junta de Comunidades para conseguir una revitalización de sus centros históricos. Finalmente, el proyecto URBSPAIN asume una metodología común de "case studies", y nuestra investigación se centra en el análisis de dos estudios de caso a escala micro en Castilla-La Mancha. No se trata de analizar la recuperación funcional de unos 
espacios urbanos, de los Centros Históricos de Cuenca y Toledo, sino de abordar una aproximación crítica a unas instalaciones socioculturales de nueva planta, desde que surge la idea hasta que abre sus puertas al público, desde su diseño a su gestión, desde el impacto visual al impacto económico.

Para comprobar las hipótesis aquí planteadas, para analizar hasta qué punto los equipamientos socioculturales han provocado o pueden provocar la potenciación funcional de los centros históricos de las ciudades Patrimonio de la Humanidad en Castilla-La Mancha, la investigación se divide en dos partes autónomas. En la primera, de investigación básica, se incide en la política urbana regional destinada a la revitalización de estos espacios y en el planeamiento especial de los centros históricos de Cuenca y Toledo. En la segunda, más práctica, se presentan dos proyectos urbanos de nueva planta asociados a usos socioculturales, dos estudios de caso a escala micro, la construcción del Teatro-Auditorio de Cuenca realizado por José María García de Paredes y del Palacio de Congresos de Toledo "El Greco", del arquitecto y Premio Príncipe de Asturias Rafael Moneo. En esta segunda parte trataremos de descender al detalle, a la toma de decisiones, a los proyectos, a su implementación, su gestión y los posibles efectos negativos de los mismos. Se trata de estudiar dos proyectos, dos equipamientos socioculturales polémicos, cada uno en su momento, y dilucidar si estos son instrumentos idóneos por sí solos para dinamizar o regenerar los espacios en donde se asientan.

En esta fase del proyecto, de carácter marcadamente cualitativo, hemos abordado la recopilación, tratamiento y análisis de las siguientes fuentes indirectas: documentos de planeamiento (planes generales de ambas ciudades y planeamiento especial de ambos espacios históricos), normativa de la política urbana regional e informes y documentos internos de carácter administrativo como son las expedientes del proyecto de construcción del Teatro-Auditorio de Cuenca y el Palacio de Congresos de Toledo "El Greco". A éstas se sumarían otras fuentes como noticias de prensa, sobre todo local, radio y televisión.

En lo referente a las fuentes indirectas, la técnica empírica empleada para cumplir este objetivo ha sido el trabajo de campo pues permitió aproximarse a la temática investigada, principalmente a través de fuentes orales, constituidas por los testimonios de los distintos actores involucrados en la promoción, gestión y uso de los equipamientos seleccionados como estudios de caso, recogidos a través de la técnica de la entrevista semi-estructurada en profundidad a informadores cualificados. Las entrevistas en profundidad, seis por cada estudio de caso, se plantearon a distintos tipos de interlocutores: administraciones públicas, sector económico y asociacionismo. En definitiva, seis entrevistas semi-estructuradas entre una muestra de informantes clave: el presidente de la asociación de vecinos 
del casco antiguo de Cuenca, el presidente de la asociación de vecinos "La Cornisa" del casco histórico de Toledo, un comerciante del casco histórico de Cuenca y un artesano-comerciante de la zona de Las Tendillas de Toledo, los gerentes de los consorcios de ambas ciudades, el director y el coordinador de actividades del teatro-auditorio durante el período 1994/2008, la actual concejal de cultura del ayuntamiento de Cuenca y responsable de la Fundación de Cultura "Ciudad de Cuenca" y el gerente de la Empresa Municipal de la Vivienda de Toledo, a quienes sus experiencias y/o cargos les proporcionan una visión de conjunto enriquecida en muchas ocasiones con la capacidad de análisis diacrónico.

En cuanto a la mecánica utilizada para la realización de las entrevistas, se optó por un guión escrito y la grabación de las respuestas para su ulterior procesamiento y explotación. Respecto al contenido de las mismas, el hilo conductor lo constituirían nueve criterios previamente establecidos por el grupo de investigación para poder valorar las actuaciones sobre las que estamos trabajando: percepción por el entrevistado del grado de impacto de la actuación, carácter integrado y transversal en el marco de una política urbana integral, carácter trasferible, carácter innovador, sostenibilidad ambiental, repercusión de las actuaciones sobre la imagen de la ciudad, colaboración y coordinación interinstitucional, aplicación del principio de la gobernanza, y avances alcanzados. Estos criterios cumplen la función de concretar el problema a estudiar, y "ayudarán a estructurar las observaciones, las entrevistas y la revisión de documentos" (STAKE, 1995: 29). Su función es, según Yin (1994), encaminar la investigación en la dirección correcta mostrando aquello que es necesario observar para obtener evidencias y evitar "recogerlo todo". En nuestro caso, la finalidad de los mencionados criterios era el poder estructurar, con una cierta homogeneidad, las entrevistas a los actores involucrados en la actuación, adaptándolos a cada caso y situación.

Una vez realizada la entrevista se procedió por parte del investigador a la valoración de cada uno de los criterios entre 0 y 5 , para posteriormente analizar transversalmente cada de ellos en los seis entrevistados y proceder a una calificación media de todos y cada uno, siendo el objetivo último la valoración de ambas intervenciones para determinar si son buenas prácticas, malas prácticas o sus variantes intermedias.

Además, los resultados obtenidos en las entrevistas fueron contrastados con la realidad empírica observada durante el trabajo de campo y con las informaciones y opiniones a las que se tuvo acceso a través de los medios de comunicación, prensa local, o las conversaciones espontáneas con la población de la zona. Todos estos datos, una vez sistematizados, analizados e interpretados posibilita- 
ron una construcción aproximada de la realidad que nos esforzamos por explorar, conocer, comprender y explicar.

\section{LA POLÍTICA URBANA. CASTILLA-LAMANCHA A PLENA LUZ.}

El preocupante estado de conservación de los edificios y monumentos de las ciudades de Cuenca y Toledo hicieron que la Junta de Comunidades de Castilla-La Mancha, y más en concreto la Consejería de Educación y Cultura, elaborara en 1989 el programa "Castilla-La Mancha a Plena Luz". A Plena Luz es un programa integral articulado en torno a cinco subprogramas: la rehabilitación de viviendas, la mejora del paisaje urbano, la potenciación del equipamiento sociocultural, la restauración monumental y la redacción del Plan Especial. En definitiva, se trata de un programa de intervención que intenta articular las actuaciones en lo residencial, el equipamiento, las zonas libres y lo monumental, como elementos estructurantes de la trama urbana. El objetivo es el mantenimiento de la realidad social y la realidad física, y para ello se han incentivado las actuaciones de rehabilitación de la iniciativa privada, a través de la intervención pública.

Con las intervenciones realizadas en el marco de esta iniciativa regional no solo se pretende recuperar el patrimonio físico o monumental de inmuebles vacíos o infrautilizados, sino también impulsar, con su reutilización, la revitalización de la ciudad antigua como motor de desarrollo para la creación de nuevas actividades. Además del efecto inducido provocado en la potenciación turística de este espacio urbano, hay que resaltar el importante papel desempeñado en la generalización de las actuaciones de rehabilitación en las zonas donde se abordan. A Plena Luz ha inducido la inversión privada para el acondicionamiento de viviendas, ha facilitado el cambio de uso en algunos inmuebles y ha producido una incipiente revitalización. Las actuaciones del mencionado programa regional han revalorizado la imagen simbólica, cultural y turística en el caso de Cuenca, y potenciado el Centro Histórico de Toledo como un centro fundamentalmente terciario.

Esta política urbana regional recoge entre sus objetivos la redacción y aprobación de los correspondientes Planes Especiales, con el objetivo de establecer el marco de actuación de las intervenciones urbanísticas en los centros históricos regionales Patrimonio de la Humanidad. Como consecuencia de la aplicación de estas políticas y de la entrada en vigor de los planes especiales diseñados para estos espacios urbanos, se ha conseguido una importante recuperación física del patrimonio monumental y numerosos cambios funcionales del patrimonio arquitectónico. 


\section{EL PLANEAMIENTO ESPECIAL Y LA POTENCIACIÓN DE LOS USOS SOCIOCULTURALES.}

La necesidad de abordar la redacción y aprobación de un planeamiento especial que regulara las intervenciones en los centros históricos de las ciudades castellano-manchegas Patrimonio de la Humanidad, se ha manifestado en distintos documentos de planeamiento general que demandaban unos más específicos para los centros históricos.

La declaración de la ciudad de Toledo como Monumento Nacional en 1940 provoca la redacción del Plan General de 1943, único documento de planeamiento que ha formulado propuestas concretas para el casco histórico. En 1963 se plantea de nuevo la redacción del Plan General de Ordenación Urbana. Este Plan, según Almarcha (2011), refleja los conceptos generales de la época: la separación entre los aspectos urbanísticos y los referentes al patrimonio histórico y el concepto de una ciudad sobredimensionada en sus áreas exteriores, que llevará a potenciar de forma muy notable el despoblamiento de la ciudad histórica. En definitiva, esta zona ha perdido prácticamente el uso residencial tradicional, presentando una clarísima terciarización en relación con su carácter de capital regional y con el importante turismo que atrae. Durante muchos años, las actuaciones en el casco histórico de Toledo se rigen por los criterios establecidos por las diferentes Comisiones de Patrimonio. La situación de ambigüedad urbanística se vio paliada con las Instrucciones de Bellas Artes de 1968, que intentan clarificar los criterios de actuación en el conjunto histórico con prescripciones más claras de carácter volumétrico y estético, y que se convertirían de hecho en las Ordenanzas del Casco Histórico. Por fin, el Plan General Municipal de Ordenación Urbana de Toledo de 1986 considera que el desarrollo del Conjunto Monumental debe estar regulado por un planeamiento especial, aunque tanto este como el anterior eluden el problema.

Por lo que respecta a la ciudad del Júcar, el Proyecto de Ordenación de la Ciudad de 1943 apenas tuvo en cuenta aspectos relacionados con el Casco, tales como la mejora de accesos, la dotación y mejora de servicios, la consolidación de edificios, la urbanización, etc., necesarios para mantener su función residencial. El Plan General de Ordenación Urbana de 1963 lejos de resolver los problemas de los barrios extramuros los considera a extinguir en su mayor parte. Este Plan se revisó, modificó y aprobó en los años 1976, 1988 y 1996. Ante la gravedad de la situación, la revisión del Plan General de 1976 señalaba que no podía ser una buena política de revitalización aquella que permitiera que se perdiera el paisaje urbano singular. De ahí que en estos planes se introdujera una ordenanza específica de Casco Antiguo que intentaba regular las actuaciones que pudieran 
realizarse en este espacio. La revisión del Plan General de 1988 sigue en la línea de conservación pasiva, manteniendo la ordenanza para el casco antiguo e indicando que los aspectos formales y compositivos los establecerá el Plan Especial. El 26 de agosto de 1996, unos meses antes de declarar al Casco Histórico y sus Hoces Patrimonio de la Humanidad, se aprueba el Plan General del Municipio de Cuenca, en la que no se establece ninguna ordenanza en cuanto a la protección del casco antiguo, remitiéndose a la de 1988.

Según Carrasco Parrilla (2008), los planes generales que han regulado la actividad urbanística de la ciudad de Cuenca, o no han recogido de manera expresa una preocupación por la conservación del casco antiguo, o se han centrado en la rehabilitación y remodelación de edificios históricos, sin prestar la atención merecida a la revitalización del mismo.

En 1997 y 2002, doce años y seis años después de ser calificadas por la UNESCO Patrimonio de la Humanidad, el pleno del ayuntamiento de Toledo y el de Cuenca, respectivamente, dieron luz verde a sus respectivos planes especiales de casco histórico. Ambos tienen como objetivos el mantenimiento del casco como espacio multifuncional, la integración de los espacios infrautilizados con nuevas funciones y el aprovechamiento del turismo y lo cultural para impulsar la revitalización de estos espacios. El Plan Especial del Conjunto Histórico de Toledo tiene por objeto la protección del área afectada por la declaración de Conjunto Histórico. El ámbito de la declaración incluye al conjunto del casco histórico en su zona intramuros, por lo que quedaría fuera el barrio de Covachuelas. En el Plan Especial de Cuenca se han tenido en cuenta tanto los límites señalados en el Plan General, como los definidos en el expediente de declaración de Recinto Histórico-Artístico y la declaración de Paraje Pintoresco de las Hoces del Huécar y del Júcar, incluyendo estos dos espacios en la regulación urbanística del casco.

En Toledo, el Plan Especial contempla un Catálogo Monumental y un Catálogo Residencial, y distingue entre casona o palacio, casa patio, casa patio entre medianera y casas verticales, y fijan una serie de categorías de intervención desde el mantenimiento ordinario, el mantenimiento extraordinario (rehabilitación), la reestructuración edificatoria y la reestructuración urbanística. El Plan Especial realiza una valoración del paisaje urbano de la ciudad y remite a un estudio posterior concretado en el Plan de Color del Casco Histórico. En el caso de Cuenca, como documento complementario del Plan Especial se incluye el Catálogo de la Edificación, Espacios y Paisaje Urbano. Este contiene una relación de aquellos edificios que por su valor histórico o singular deben ser rescatados para usos y funciones más acordes con su categoría arquitectónica, y un fichero completo de todas las unidades edificatorias y niveles de protección, siete en total, desde la 
conservación a la obra nueva, y se define la calidad arquitectónica de cada edificio, desde lo monumental a lo neutro o nocivo.

El Plan tiene como objetivos el fortalecimiento de la residencia como actividad básica del casco, la puesta en valor del patrimonio existente y la proyección de Toledo como capital monumental con funciones culturales, representativas, residenciales, turísticas y administrativas. Estas funciones han de asegurar el mantenimiento de la singularidad monumental de Toledo con un rol activo de centro de un hinterland territorial amplio (Peris, 2006; Almarcha et al, 2011), mediante la incentivación y diversificación de las actividades centrales y de servicio en relación con otras ya instaladas en el casco, como la universitaria o la administrativa. Para ello y en relación con el tema que nos ocupa, está contemplada la construcción del palacio de congresos además del centro cultural de San Marcos, el archivo municipal y la nueva biblioteca regional. Otro aspecto relacionado con la pluriactividad es el que hace mención a las medidas tomadas o programadas para mejorar el acceso y la movilidad del tráfico rodado en su interior. A este respecto, el Plan Especial aboga por diversas actuaciones en materia de tráfico y aparcamiento plasmadas en un Programa de Infraestructuras con tres modalidades de actuación: ensanchamientos viarios, aparcamientos de borde de carácter disuasorio y unas escaleras mecánicas, ya construidas, desde el pie de la muralla en el Paseo de Recaredo.

Los objetivos del Plan Especial del Casco Histórico de Cuenca pueden concretarse en la recuperación demográfica mediante el estímulo de la función residencial y de la política de rehabilitación, el estímulo del comercio relacionado con las funciones residencial, sociocultural, educativa y turística del Casco, el cambio funcional de edificios religiosos, el impulso del transporte colectivo y el diseño de propuestas de peatonalización. Por último, los objetivos en cuanto a comunicaciones y accesibilidad van encaminados a la corrección de la problemática propia de la especial ubicación y morfología del casco histórico y de las características de su red viaria, y a resolver la demanda de aparcamiento que exige la revitalización de este espacio. Como puntos principales pueden destacarse las propuestas de creación de aparcamientos para residentes y aparcamientos disuasorios del uso del vehículo para los visitantes, algunos ya ejecutados como el aparcamiento del Huécar en las proximidades del auditorio, lugar accesible en coche o autobús, que permitirá la subida a la ciudad alta mediante las escaleras mecánicas contempladas en el Plan Especial.

La relación de las ciudades históricas con el medio natural circundante ha sido un elemento básico en el diseño y redacción de los planes especiales de los centros históricos españoles, de ahí que en Toledo se proponga, como en el 
caso del Plan Especial de Cuenca, el mantenimiento de las vegas como zonas no construibles y la exigencia de un estudio de impacto ambiental en la construcción de vías de comunicación e infraestructuras urbanas de nuevos trazados. Sin embargo, y según Almarcha (2011), este requerimiento no ha dado sus frutos ya que con la llegada del AVE a la ciudad de Toledo y con el acceso desde la carretera de Ocaña se ha impactado negativamente en el paisaje de la ciudad. En Cuenca, la consideración del paisaje del casco como la suma del medio natural de las hoces y la arquitectura del recinto urbano, tiene como fin la protección del entorno natural como elemento esencial del paisaje cultural del conjunto histórico. A efectos de control y de protección del Suelo No Urbanizable (SNU) de las hoces del Júcar y del Huécar, en el Plan Especial se han señalado tres áreas diferenciadas: áreas de conservación ambiental, áreas de conservación de usos (naturales y artificiales) y áreas de recuperación ambiental o funcional (Almarcha et al., 2011). Estas últimas son las áreas de SNU en fondo de valle o en ladera, en las cuales su proximidad a las áreas más urbanizadas crea espacios de transición a lo urbano que han de ser protegidas en cuanto a su integración en el paisaje natural mediante Programas de Adecuación Ambiental. En esta zona es donde se construyó, unos años antes de entrar en vigor el Plan Especial, el auditorio de García de Paredes.

\section{INSTRUMENTOS DE GESTIÓN. EL PAPEL DE LOS CONSOR- CIOS.}

En la gestión del planeamiento especial se han ensayado caminos diversos, entre otros, comisiones de seguimiento, operaciones de actuación conjunta, agencias de renovación urbana, empresas mixtas, y consorcios (TroitiÑo, 2000). Para la gestión de los Planes Especiales de los centros históricos de Cuenca y Toledo se crearon estructuras paralelas, aunque no en el tiempo: fundaciones, reales patronatos y consorcios.

Las fundaciones están propiciando, en general, una conservación y rehabilitación del patrimonio cultural urbano más flexible y ágil. Toledo es una de las tres ciudades Patrimonio de la Humanidad que cuenta con una Real Fundación, un Real Patronato y un Consorcio, junto a Santiago de Compostela y Cuenca. La Real Fundación de Toledo, institución cultural privada constituida en 1988, tiene como fin la conservación y revitalización de la ciudad histórica de Toledo mediante actividades dirigidas a fomentar la habitabilidad de la ciudad y la protección, estudio y difusión de sus bienes patrimoniales. Su función consiste en la canalización de recursos privados a obras y actividades de interés colectivo. La subvención pública representa un porcentaje muy pequeño del presupuesto anual 
casi siempre aplicado a un proyecto concreto en el que están involucradas otras entidades. Diez años más tarde, la Real Fundación participó en la composición del Real Patronato de la ciudad de Toledo, y en el año 2004 se crea el Real Patronato Ciudad de Cuenca. Ambos tienen como fin el promover la ejecución de obras, servicios e instalaciones en general, impulsar la coordinación de las inversiones públicas, favorecer la puesta en marcha de iniciativas culturales orientadas a la conservación del patrimonio histórico y potenciar -en el caso de Toledo- la ciudad como lugar de encuentro de culturas diversas (TROITIÑo, 2000).

El ente gestor y administrativo del Real Patronato, el Consorcio de la ciudad de Toledo, se creó el 10 de enero de 2001, cuatro años antes que en Cuenca. En ellos están representados todos los niveles de la administración. De carácter público, con personalidad jurídica propia y plena capacidad de obrar, fueron creados para recuperar el patrimonio y potenciar las actividades culturales y turísticas. Entre sus fines específicos se encuentran el servir de apoyo administrativo y de gestión al Real Patronato, el promover y facilitar la coordinación de las competencias de los distintos niveles administrativos, y el ejercer todas aquellas funciones encomendadas por las administraciones consorciadas.

La puesta en marcha de los Consorcios de Toledo y Cuenca como sistemas de gestión y financiación, ha provocado un impulso notable de actuaciones en materia de rehabilitación residencial, de recuperación de elementos singulares y de revitalización de los conjuntos urbanos en general (ALMARCHA, 2011)². Los consorcios de estas ciudades han permitido acceder a subvenciones de cuatro administraciones (central, regional, provincial y local) para conservar su patrimonio monumental y para potenciar su actividad cultural y turística.

\section{ESTRUCTURA FUNCIONAL DE LOS CENTROS HISTÓRICOS.}

El conjunto histórico de Toledo, declarado en 1940 Conjunto Monumental e incluido en la Lista del Patrimonio Mundial auspiciada por la UNESCO en 1986, es desde hace mucho tiempo uno de los "hitos de referencia" del turismo cultural, una importante fuente de ingresos para la economía de la ciudad y la revitalización del casco. La llegada de cerca de un millón y medio de visitantes anuales genera un importante volumen de ingresos en los sectores de la hostele-

2 Hasta finales del año 2010, el Consorcio de Toledo subvencionó la rehabilitación (entre obras menores y mayores) de más de 2000 viviendas en el Conjunto Histórico. A esto hay que unir la rehabilitación en locales comerciales. 
ría, restauración, comercio destinado al turismo, librerías y otro tipo de establecimientos.

Según el impuesto de actividades económicas, la distribución espacial de los establecimientos comerciales, hosteleros y de servicios presenta una concentración en un eje este-oeste en la zona central, por donde discurren las rutas turísticas, mientras que los barrios del sur, más poblados, y los del norte, menos poblados, son los de menor actividad comercial. La localización de los establecimientos especializados pertenecientes a cadenas de fuerte implantación en toda España se sitúa también en la parte central del eje este-oeste, ejerciendo una atracción en toda la ciudad. La función universitaria docente está presente al igual que la administrativa potenciada esta última por la decisión de instalar la capital de la región en Toledo. Resumiendo, el centro histórico continúa siendo el centro de actividad de la ciudad, no tanto por su comercio de diario como por su especialización en funciones administrativas, docentes, culturales y económicas de carácter terciario (CAMPOS, 1999). No obstante, en el centro histórico de Toledo hay muchas carencias relacionadas con la falta de centros de salud (uno en todo el centro histórico), centros deportivos, de ocio y esparcimiento, cines, teatros y bibliotecas.

La situación del casco antiguo de Cuenca es muy similar a la de Toledo. En su estructura multifuncional son evidentes tanto las herencias del pasado, caso de las funciones religiosa, administrativa y artesanal, como los signos de los nuevos tiempos en las funciones hostelera, comercial y sociocultural. Hasta el día de la inauguración del Teatro-Auditorio de Cuenca, la vida cultural de la ciudad se reducía a la actividad generada por la asociación musical "Maestro Pradas", el Cine Club "Chaplin", y la actividad cultural programada por el ayuntamiento que se encargaba de liderar un programa llamado "Cultural Cuenca", financiado por la Junta de Comunidades de Castilla-La Mancha y la Caja de Ahorros. La actividad musical programada se desarrollaba en dos antiguas iglesias y la teatral en un antiguo cine teatro, el Xúcar. La consolidación de Cuenca como un importante centro del turismo interior y la revalorización de la ciudad alta como espacio lúdico para visitantes y vecinos de la ciudad ha propiciado una espectacular expansión de la hostelería, especialmente en lo concerniente a pequeños hoteles, bares y restaurantes. La rama de alojamientos hoteleros, hasta ahora apenas presente por los problemas de accesibilidad y de aparcamiento, tiende a consolidarse propiciando la rehabilitación de edificios infrautilizados.

La dinámica comercial de la ciudad alta durante los últimos años se ha caracterizado por la búsqueda de la supervivencia como consecuencia del reforzamiento de la función turística y el uso lúdico que de esta zona hace la juventud 
conquense, con el auge de tiendas de cerámica y artículos de regalo, talleres artesanos y tiendas de antigüedades. Por el contrario, el comercio orientado a la población residente es cada vez más precario, debido a la limitada base demográfica y a los fuertes desniveles topográficos en su estructura urbana.

\section{ESTUDIO EMPÍRICO.}

El caso más característico de edificio de nueva planta destinado a uso sociocultural en Cuenca es la construcción del auditorio -inaugurado el 6 de abril de 1994- en una antigua cantera abandonada en la Hoz del Huécar, en la falda del Cerro del Socorro, frente a la ciudad antigua y en las proximidades de las Casas Colgadas y del Parador de Turismo. El proyecto, incluido en el Plan Nacional de Auditorios, se encargó al estudio de arquitectura de José María García de Paredes que compuso un diseño de la construcción siguiendo los criterios experimentales aplicados con anterioridad en el South Bank Art Centre de Londres.

En Toledo es el nuevo palacio de congresos el caso más representativo de edificio de nueva planta destinado a uso sociocultural en el centro histórico. Construido en la roca sobre el río Tajo, se levanta en la zona del Miradero -junto a Zocodover- aprovechando el espacio donde estaban situados los antiguos juzgados y unas galerías con bares y discotecas. Inaugurado el 18 de diciembre de 2012, es obra del arquitecto Rafael Moneo y el urbanista barcelonés Joan Busquets.

\section{VI.1 Trabajo de campo. Emplazamiento y características de la intervención.}

Si bien la construcción del Teatro-Auditorio de Cuenca no está recogida en el Plan Especial, ya que cuando este se aprueba, el auditorio lleva seis años funcionando y ofertando una programación de calidad, sí aparece contemplado en el mismo como edificio de NIVEL III DE PROTECCIÓN puesto que la legislación urbanística impone la necesidad de recoger en las Ordenanzas del Plan Especial medidas de adaptación de los edificios al entorno inmediato y a las características del emplazamiento, cualquiera que sea la valoración intrínseca del edificio.

Con una localización aparentemente periférica, incorpora a la trama urbana un borde con una situación privilegiada desde donde la imagen vertical de la ciudad cobra su mayor dimensión (figs. 1 y 2). El Teatro-Auditorio de Cuenca es un espacio multiuso construido mediante un acuerdo de colaboración firmado en 1987 entre el Ministerio de Cultura (Instituto Nacional de las Artes Escénicas y la Música, 1/3), la Junta de Comunidades de Castilla-La Mancha (Consejería de Educación y Cultura, 1/3), la Diputación Provincial (1/6) y el Ayuntamiento 
(1/6). El edificio, con el que se pretende cerrar la antigua brecha abierta en el escarpe rocoso mediante la presencia de grandes volúmenes, responde al estilo geométrico de García de Paredes (fig.3). Interiormente, el edificio consta de dos salas (736 y 190 butacas respectivamente) para celebrar conciertos, teatros, conferencias, asambleas y conciertos de cámara.

Figs. 1,2 y 3. Situación y perspectivas del Teatro-Auditorio de Cuenca.
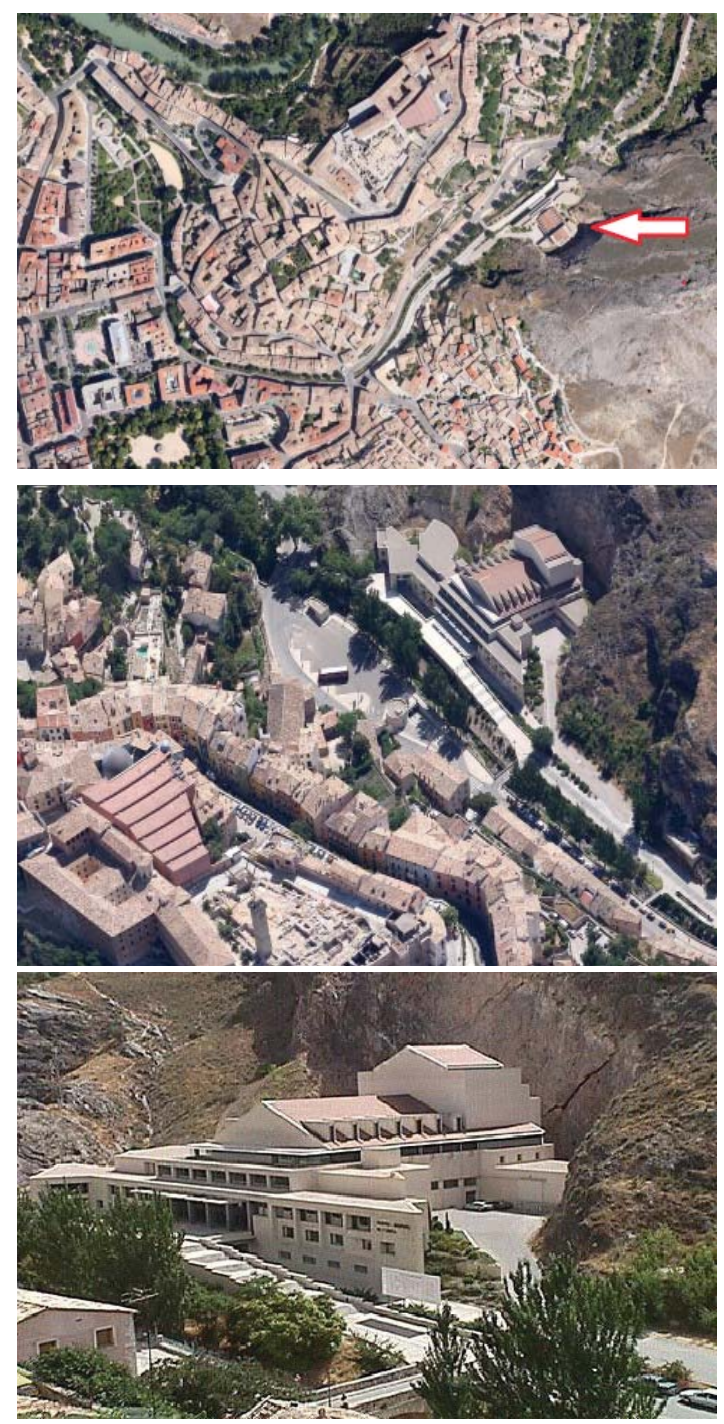

FuENTE: Auditorio de Cuenca. En línea http://www.auditoriodecuenca.es/desktopdefault. aspx?tabid $=12574$ 
Figs 4, 5 y 6. Situación y perspectivas del Palacio de Congresos de Toledo "El Greco".
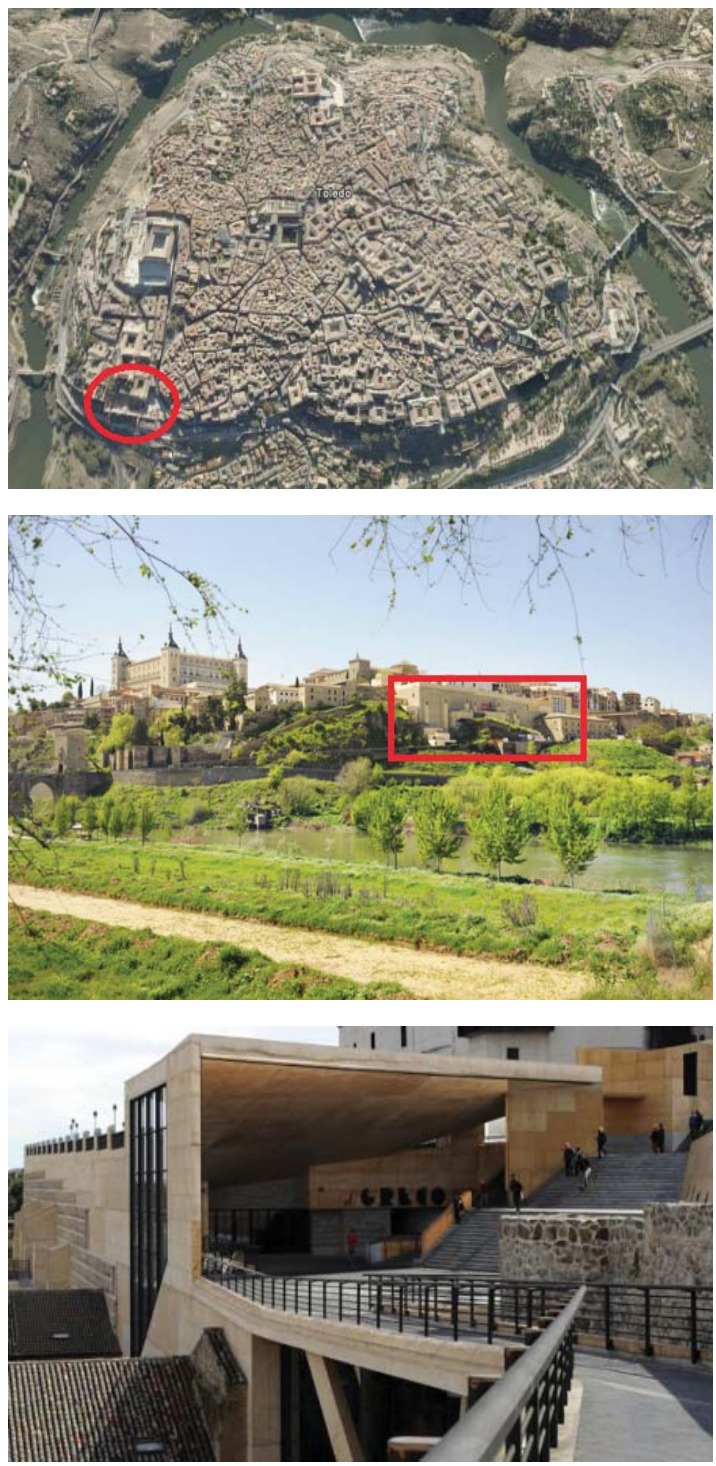

Fuente: Gestió i Serveis Trade Center S.A. (2012). Palacio de Congresos de Toledo "El Greco". Dossier de prensa. Octubre. www.pctoledo.es; www.gestioiserveis.es

En Toledo, el palacio de congresos comenzó a construirse en 2003, tras la firma de un acuerdo entre la administración regional, provincial y municipal. A 
pesar de llevar desde octubre de 2012 en funcionamiento de forma oficiosa celebrándose en él reuniones de empresas, la inauguración oficial no se produjo hasta el 18 de diciembre de 2012. Desde la cota más elevada a la más baja, junto al río, el visitante puede encontrar los jardines del Miradero, una gran zona ajardinada de uso y disfrute público como remate en la cubierta del edificio, el vestíbulo, dos plantas de restaurante, una de servicios y seis de aparcamiento. El palacio cuenta con un auditorio (con una capacidad para más de 1000 personas) y con otras siete salas con aforos que suman 1.500 asientos.

\section{VI.2 Entrevistas con los actores involucrados. Evaluación de las actuaciones seleccionadas.}

VI.2.a. Criterio 1: Percepción del grado de impacto que haya podido tener la actuación.

Ambas actuaciones han tenido algunos puntos conflictivos en relación con el diseño del edificio, la adecuación al entorno y la cuestión presupuestaria. Los dos equipamientos han sido abordados en una zona periférica de sus cascos históricos. En Cuenca, al otro lado del río Huécar, en una cantera abandonada en la hoz, y en Toledo en el escarpe del resalte rocoso, dentro del meandro del Tajo. Estos emplazamientos han tenido y tienen una repercusión importante en la imagen del casco: en el primer caso en la imagen "desde el casco", desde la cornisa construida de la hoz, y en el segundo caso en la imagen que se tenía del casco en su cara norte. La consideración del impacto visual es muy dispar entre los entrevistados; hay quien piensa que el revoco del palacio de congresos responde a la necesidad de buscar una textura y un color que no desentonaran con el resto de construcciones, pero según la mayoría de los entrevistados, la imagen de la ciudad se ha alterado por el diseño de esa pieza. La fachada del palacio de congresos debería haberse formalizado "como un elemento más del límite de la ciudad antigua. Su aspecto de muralla con contrafuertes puede ser una buena idea, pero el hecho es que a veces, por el material empleado o por su mayor escala, destaca demasiado y parece una entrada visual un tanto discordante, imponiendo sin miramientos su gran presencia en un tejido fragmentado"3. No obstante, las obras de estos arquitectos, según el gerente del Consorcio ciudad de Toledo "necesitan más tiempo para asentar y fijar sus imágenes".

La percepción de los entrevistados del grado de impacto del Teatro-Auditorio de Cuenca en aspectos urbanísticos, sociales, económicos o de mejora de la

3 HERNÁNDEZ, M. (2013): "Nuevo palacio de congresos en Toledo". Engawa. Disponible en http://www.engawa.es/index.php?/project/16--nuevo-palacio-de-congresos-en-toledo/ 
calidad vida de los habitantes, son muy positivas. Quizá esta visión esté relacionada con el tiempo transcurrido desde su inauguración y la buena programación ofertada. Los veinte años que lleva en funcionamiento han podido facilitar la asimilación del edificio con el entorno, asimilación o integración inexistente en un primer momento y que generó una fuerte polémica en la ciudad. Todos los entrevistados lo consideran un "edificio con mucha personalidad", "totalmente integrado en el paisaje del entorno". No se trata de una imitación o reconstrucción histórica, sino de un edificio de nueva planta con un diseño, según la actual gerente, "completamente moderno e intemporal, o atemporal, porque ya han pasado veinte años desde su construcción y parece recién inaugurado". La totalidad de los entrevistados lo consideran bien diseñado y proporcionado para la población de la ciudad, un edificio "para verlo por dentro y desde dentro a fuera, por la perspectiva del casco histórico en este punto de la hoz".

En cuanto al impacto urbanístico, al situar el edificio en un punto de la salida de la ciudad hacia la hoz del Huécar, urbanizándose toda la margen izquierda del río, este espacio se ha convertido en un paseo peatonal que mejora la calidad del barrio, permite su uso por los vecinos y por los ciudadanos en general y sirve en ocasiones como espacio donde instalar y celebrar pequeñas ferias y mercadillos medievales. La ubicación junto a un aparcamiento, con una plataforma amplia en superficie para el estacionamiento de autobuses, lo ha convertido en uno de los puntos de referencia para el acceso al casco antiguo.

La percepción del palacio de congresos no ha sido tan positiva como en el caso de Cuenca, quizá por lo reciente de su inauguración y el escaso tiempo transcurrido para asimilar esta construcción. Frente a los que lo consideran "una de las mejores soluciones para la topografía del lugar, bien integrado, fusionado con el entorno y bien resuelto", opinión esta última del arquitecto y de los políticos entrevistados, se encuentran aquellos que lo identifican como una "aberración urbanística", sin duda "una de las peores actuaciones realizadas en Toledo, sin lograr la pretendida integración en el espacio"4. Muchos se preguntan por qué se realiza este tipo de intervenciones cuando "a la sociedad toledana se le obliga a conservar en sus casas los más mínimos detalles decorativos". Para éstos, "el paseo del Miradero era mucho más acogedor". Podría haberse realizado "un palacio de congresos más económico, con otra estética, aunque no se hubiera tenido un edificio de Moneo". Otros muchos han quedado gratamente sorprendidos por la amplitud de las instalaciones cuando las comparan con los recuerdos de la vieja

4 UrbanScraper Arquitectura+Urbanismo+Ingeniería. "Futuro Palacio de Congresos de Toledo. Moneo (Spain)". Publicado por FOLK en 30.4.07. Disponible en http://www.urbanscraper. com/2007/04/futuro-palacio-de-congresos-de-toledo.html

Polígonos. Revista de Geografía, 25 (2013); 19-56 
galería comercial en la que todo parecía demasiado estrecho y oscuro. Moneo presenta esta intervención como "una oportunidad para mejorar los equipamientos de la ciudad, en pleno Casco Histórico de Toledo, sin romper la imagen de la ciudad imperial". Plantea la intervención como fundamental "para fortalecer las opciones de Toledo a nivel económico y cultural", y considera un acierto el haber pensado "enmendar y usar de mejor modo un borde de muralla tan destacado e importante"s.

Un aspecto reiterativo en todas las entrevistas realizadas a los actores urbanos de Toledo, como en el caso de Cuenca, es la importancia concedida a las manifestaciones secundarias asociadas al palacio: aparcamiento, salón de exposiciones, centro de congresos, salas de reuniones, restaurante y terraza. No obstante, en Toledo las opiniones son más contrastadas. Frente a los que consideran esta intervención necesaria para la ciudad, se encuentran los que recurren a las carencias del centro histórico para argumentar que un palacio de congresos de esta envergadura era innecesario, más si tenemos en cuenta la existencia de teatros como el Teatro de Rojas y algunas salas de entidades bancarias. La percepción del entrevistado del grado de impacto del palacio de congresos se ve bastante diluida por el tiempo transcurrido desde la instalación de la primera piedra a la inauguración del edificio. Además, el complejo del palacio de congresos ha sido objeto de varias inauguraciones: en marzo de 2009 se abrió el aparcamiento subterráneo y las escaleras mecánicas que llevan hasta los aledaños de la céntrica plaza de Zocodover, y en noviembre de 2012 la sala principal, aunque todavía no se había abierto al público el restaurante ni otras piezas también importantes del comple$\mathrm{jo}^{6}$. Con esta intervención se ha creado un nuevo acceso al casco histórico y una nueva plaza pública, con gran aceptación entre los propios vecinos y visitantes según conversaciones espontaneas mantenidas en la zona.

La construcción de una obra de tal envergadura, que se ha prolongado en el tiempo más de lo esperado y cuyo presupuesto se ha disparado respecto al estipulado en el proyecto, tampoco ha tenido una repercusión acorde con esos parámetros en el aspecto social, pero también en este caso hay que tener una perspectiva temporal más amplia para poder valorar los resultados. El palacio lleva apenas un año funcionando y, por consiguiente, todavía no sabemos cuál va

5 Vida y estilo. Terra. es. "Rafael Moneo añade un "Greco" a su colección de edificios". 18 de diciembre de 2012. Disponible en http://vidayestilo.terra.es/casa/rafel-moneo-anade-un-grecoa-su-coleccion-de-edificios,8b4392d3dc6ab310VgnCLD2000000dc6eb0aRCRD.html

6 EL DIGITALCLM. Castilla-La Mancha. "El Palacio de Congresos, nueva y potente infraestructura en el corazón histórico de Toledo". 01/03/2014. Disponible en http://www. eldigitalcastillalamancha.es/el-palacio-de-congresos-nueva-y-potente-infraestructura-en-elcorazon-historico-de-toledo-123003.htm 
a ser la capacidad operativa del mismo para crear una clientela de congresos en la ciudad de Toledo.

Respecto a la ciudad de Cuenca, gracias a conversaciones informales mantenidas con conquenses y visitantes, hemos podido comprobar que el impacto social del teatro-auditorio ha sido positivo para la ciudadanía en general, para los visitantes de otras ciudades que vienen en busca de una oferta cultural de calidad y asequible, y para los vecinos del barrio como se desprende de la entrevista realizada al presidente de la asociación de vecinos. La inauguración del auditorio, según el técnico entrevistado, "marcó un hito en la vida cultural de esta ciudad, un antes y un después, fue un auténtico boom, un auténtico revulsivo desde el punto de vista cultural, abriéndose un auténtico abanico de posibilidades culturales para la ciudad".

En relación con el impacto económico del auditorio en Cuenca, el turismo de congresos y la presencia de visitantes de regiones próximas, fundamentalmente madrileños y valencianos, ha sido en algunos momentos importante, "pero realmente no se ha explotado de forma organizada, promoviendo paquetes turísticos y haciendo publicidad a nivel nacional". En Toledo todos los entrevistados coinciden en destacar al sector hostelero como el más favorecido y el que más se beneficiará de la existencia del palacio de congresos, no obstante tendremos que esperar unos años para poder valorar si esta actuación repercutirá en el dinamismo del comercio del casco. El anuario económico y social de 'la Caixa' viene a confirmar con cifras la situación de crisis del sector comercial que nos comenta el presidente de una asociación de vecinos y un artesano de la zona de Tendillas: "el cierre de negocios es constante", "los ingresos de los comerciantes no son como los de antes", "el damasquino y la cerámica, productos estrella en la venta a turistas hasta hace unos años, tienen poca salida en la actualidad". Precisamente el sector espera la elaboración de un plan estratégico encargado a la Federación Empresarial Toledo.

Lamentablemente su puesta en funcionamiento, según el gerente de la Empresa Municipal de la Vivienda (EMV), ha coincidido con una coyuntura de crisis económica y, por consiguiente, hasta ahora no se ha aprovechado todo su potencial. Además, según sectores de la oposición en el ayuntamiento de Toledo, existe una falta de interés en materia turística y en la promoción económica del centro histórico.

VI.2.b. Criterio 2: Carácter integrado y transversal de las acciones en el marco de una política urbana integral.

El Teatro-Auditorio de Cuenca, según la mayoría de los entrevistados, no se construyó en el marco de una política urbana integral ni de un planeamiento es- 
pecial como ocurrió en Toledo. El edificio se construyó porque Cuenca se quedaba sin infraestructuras teatrales. No obstante, en el caso de la capital conquense, el Plan de Dinamización Turística, aprobado en 1998, ha contribuido a acondicionar la ciudad y, especialmente su casco antiguo, como un destino atractivo y de calidad, y ha desbordado, aunque de una forma tímida, el ámbito de la planificación turística al adaptar el patrimonio cultural como recurso turístico y adecuar el auditorio del Huécar como sala de congresos en el marco del programa "Mejora del Producto". El programa de gestión ha permitido, entre otros logros, la creación y puesta en marcha de la Fundación Cuenca Ciudad de Congresos, y el de "Promoción, Comunicación y Comercialización", con una orientación turística más sectorial, ha contribuido a la creación de una imagen de marca e identidad corporativa, a la que también ha contribuido el teatro-auditorio (Troitiño, 2006).

Por otro lado, el complejo del palacio de congresos (aparcamiento, acceso mecánico al casco, palacio de congresos, auditorio, plaza) se inscribe dentro del Plan de Renovación Urbana de Toledo puesto en marcha por el ayuntamiento de la ciudad en 2010, tras solicitar a los colectivos vecinales su participación para determinar las prioridades y las necesidades más importantes de cada barrio ${ }^{7}$.

Además, como ya se ha apuntado, su construcción ya estaba recogida en el Plan Especial. Respecto al carácter transversal, todavía es pronto para ver los efectos del palacio; no obstante, si lo que se pretende con esta actuación es potenciar el turismo de congresos, la cercanía a Madrid puede favorecer la consecución del objetivo. Sin embargo, y según algunos, quizá lo mejor de la intervención sea el aparcamiento y el remonte asociado el palacio, que salva un desnivel de 150 metros desde el río a la plaza de Zocodover, el centro de la ciudad.

VI.2.c. Criterio 3: Carácter transferible o de efecto demostración de las acciones, traducido en reconocimiento nacional o internacional, del que se pueda inferir su potencial aplicación a otras experiencias locales en curso o previstas.

En Cuenca todos consideran el auditorio "un ejemplo de actuación exportable", "a tener en cuenta en casos similares", "un modelo de infraestructura sociocultural para una ciudad de tipo medio o pequeño", "un ejemplo de integración urbanística a imitar", "de aprovechamiento de espacio y mejora de entorno". El Teatro-Auditorio de Cuenca, al ser la sede de la Fundación Cultura Ciudad de Cuenca, programa actos culturales de alcance local, regional, nacional e interna-

7 ABC.es. "Los vecinos colaborarán en un plan de renovación urbana", 09/11/2010. Disponible en http://www.abc.es/20101109/toledo/vecinos-colaboraran-plan-renovacion-20101109.html 
cional como la Semana de Música Religiosa (SMR), que este año celebra su 53 edición con la colaboración del Museo de Arte Abstracto, la iglesia de Valeria y la Fundación Antonio Saura, y tendrá lugar en diferentes localizaciones históricas de la ciudad (entre ellas el teatro-auditorio), en el mismo entorno urbano donde se celebran en paralelo las procesiones de Semana Santa declaradas de Interés Cultural. La celebración de la 53 SMR en todas estas instalaciones "ejemplifican perfectamente la unión entre lo histórico y lo contemporáneo". Este ambiente único junto con una programación ambiciosa sitúa la $53 \mathrm{SMR}$, una vez más, en el punto de mira del mundo musical internacional"s.

El palacio de congresos "no se considera una actuación con especial carácter demostrativo, aunque ciertamente es singular por su localización y por integrar aparcamiento, equipamiento congresual y cultural y espacio de uso público en un solo edificio". Era una necesidad perentoria el crear un palacio de congresos en un punto céntrico para dinamizar este espacio, y para ello se planteó la construcción de un complejo con aparcamientos y remontes con el fin de facilitar la accesibilidad no solo del edificio, sino del centro histórico de la ciudad. Se trataba de traer al centro las actividades congresuales que hasta entonces se celebraban en el hotel Beatriz o en el Hilton, en zonas alejadas del casco. Pero todavía es pronto para ver el efecto inducido por la programación del palacio de congresos en la ocupación de los hoteles del casco como Alfonso VI, Santa Isabel o Eugenia de Montijo: "el único congreso que se ha celebrado hasta la fecha sí ha tenido una repercusión importante en este sentido". El diseño del edificio, el periodo de ejecución y el coste final (50 millones de euros, el doble de su presupuesto inicial) juegan en contra de la aceptación del edificio haciendo que no sea un modelo a seguir. El emplazamiento era difícil, en un entorno natural y en un extremo del casco, en su periferia. Lo único positivo a resaltar sería el aparcamiento y los remontes que facilitan su accesibilidad, y la disponibilidad de un lugar donde celebrar congresos, aunque "la escala no es la más apropiada para una ciudad de algo más de 80.000 habitantes", según el gerente del Consorcio.

VI.2.d. Criterio 4. Carácter innovador de las actuaciones a nivel de proyecto, de ejecución material o de resultados alcanzados y en qué aspectos concretos se fundamentaría su condición innovadora.

El Teatro-Auditorio de Cuenca ha tenido una repercusión positiva clara e indudable. Fue uno de los primeros auditorios construidos en España, y actual-

${ }^{8}$ Hoyesarte.com. "La Semana de Música Religiosa de Cuenca, con El Greco" 18/02/2014. Disponible en http://www.hoyesarte.com/evento/2014/04/el-greco-estara-presente-en-la-semanade-musica-religiosa-de-cuenca/

Polígonos. Revista de Geografía, 25 (2013); 19-56 
mente un ejemplo de arquitectura contemporánea que forma parte del "paisaje histórico". El hecho de poder ser visto desde el propio casco antiguo, de ser una de las perspectivas desde la cornisa del Huécar, ha provocado la integración del edificio en el paisaje. Los aspectos más innovadores son los relacionados con la arquitectura del edificio y la concepción del espacio.

Las opiniones son totalmente opuestas en el caso de Toledo. La idea más generalizada, pero no compartida por los políticos entrevistados, es que "no se ha innovado en el proyecto ni en los resultados alcanzados". Quizá lo dilatado del tiempo de ejecución haya contribuido a ese convencimiento. Según María Luisa Cerrillos (2012), el error de algunas disposiciones de las ordenanzas de los conjuntos históricos es identificar el centro histórico con la estética de un determinado momento de su historia, y eso es lo que ha ocurrido con el centro histórico de Toledo y el "mudéjar". Toledo era una ciudad llena de color según los libros antiguos y los dibujos de los cantorales, pero en las últimas décadas se ha revestido de ladrillo y mampostería, y esto es lo realizado, según algunos entrevistados, en el palacio de congresos pero con hormigón coloreado y con piedras. Los materiales utilizados "no son innovadores, lo de siempre puesto de otra manera, ha faltado bastante imaginación e, indudablemente, está fuera de escala". Por tanto, no se puede considerar un edificio innovador, sino "una forma de mimetismo con distinta escala y con un resultado no demasiado agraciado". Quizá la solución de la terraza sería lo más interesante para la ciudad junto con la integración en un equipamiento sociocultural de elementos que facilitan la accesibilidad al centro histórico.

VI.2.e. Criterio 5. Sostenibilidad ambiental de las actuaciones, destacando los aspectos concretos más relevantes en que se haya plasmado (energía, agua, espacios verdes, ruido, contaminación etc.)

En la construcción del Teatro-Auditorio de Cuenca no se tuvieron en cuenta criterios relacionados con la sostenibilidad del edificio. El clima de la ciudad de Cuenca, con inviernos largos, las dimensiones del edificio y las grandes superficies acristaladas disparan el gasto energético. Como consecuencia, uno de los grandes problemas a los que tienen que hacer frente sus gestores es el mantenimiento del edificio. El paseo peatonal y el tratamiento vegetal de las márgenes del río han aumentado la superficie arbolada y las zonas de sombra. La apertura de una calle peatonal, una calle "paseable", se ha proyectado aprovechando el curso del río Huécar, con espacios verdes integrados, agradables a la vista desde la parte alta, con poco ruido y sin contaminación. No obstante, y según el Gerente del Consorcio, "no se ha aprovechado suficientemente el potencial del río, que hubiera debido integrarse más en la actuación". 
Frente a esta situación, en el Palacio de Congresos de Toledo "El Greco", y como nos asegura el gerente de la EMV, "se ha tenido presente un criterio de ahorro y eficiencia energética". En los espacios verdes que coronan el edificio, y lo aíslan, se ha buscado un bajo mantenimiento con la instalación de un jardín de boj. Por otra a parte, la oferta de un gran número de plazas de aparcamiento y las escaleras mecánicas propicia una movilidad no motorizada en el centro histórico. Sin embargo, la mayoría de ciudadanos y visitantes no las conocen y siguen aparcando habitualmente en el aparcamiento del Alcázar, en lugares de libre regulación fuera del casco, en las proximidades del Circo Romano o en el paseo del Carmen, aunque estos dos espacios ya han sido cerrados. Lo incomprensible es que el aparcamiento del palacio de congresos siga vacio o infrautilizado, aunque quizá la falta de señalización sea la causa de esta situación.

Por otra parte, GIS Trade Center acaba de recibir de TurEspaña y la Federación Española de Municipios y Provincias (FEMP) el diploma de reconocimiento al compromiso para la mejora de la calidad — Sistema Integral de Calidad Turística en Destinos (SICTED) - por su gestión del palacio de congresos con criterios medioambientales 9 .

\section{VI.2.f. Criterio 6. Repercusiones de las actuaciones sobre la imagen de la ciudad.}

Todos los entrevistados coinciden en valorar con un 5, con la puntuación máxima, la repercusión que el teatro-auditorio ha tenido en la imagen de la ciudad, adquiriendo prestigio por contar con uno de los pocos auditorios de carácter nacional. El edificio es considerado un referente de la ciudad. Muy pronto se integró en la Red Española de Teatros, Auditorios, Circuitos y Festivales de Titularidad Pública ${ }^{10}$, llevando implícita una importante publicidad y su proyección a escala nacional. Por sus escenarios han pasado artistas internacionales, que han atraído a muchos aficionados a la música y al teatro de otras provincias de Castilla-La Mancha e incluso de otras comunidades, que comentaban "la suerte de los conquenses de poder disfrutar de espectáculos de esa calidad y con esa facilidad", con "entradas baratas y casi seguras, a cinco minutos de casa". Los ciudadanos

9 Conexo.net. Diario online de Congresos, Reuniones e Incentivos. "La calidad del Palacio de Congresos "El Greco" de Toledo recibe el reconocimietno de TurEspaña y la FEMP con el SICTED”. 27/02/2014. Disponible en http://www.nexotur.com/conexo/calidad/palacio/congresos/ lsquo/grecorsquo/toledo/recibe/reconocimiento/turespantildea/femp/sicted/65536/

${ }^{10}$ Asociación cultural sin ánimo de lucro constituida en febrero del año 2000, mediante un convenio de Colaboración con el INAEM (Instituto Nacional de las Artes Escénicas y de la Música), Ministerio de Educación Cultura y Deportes. Disponible en http://www.redescena.net/lared/ quienes_somos/index.php\#faq1 
"lo acogieron con entusiasmo", "se identifican con su teatro", "lo consideran algo propio y se sienten orgullosos de contar con este espacio". De hecho, la iniciativa puesta en marcha desde la dirección de promover un club de amigos del TeatroAuditorio de Cuenca tuvo una buena acogida en la sociedad conquense.

Respecto al nuevo palacio de congresos, todavía es pronto para valorar sus repercusiones aunque, evidentemente, puede potenciar el carácter de la ciudad como destino congresual y de espectáculos de un mayor nivel y atractivo, aspectos que reforzarán a Toledo como destino de turismo cultural urbano.

Según la opinión de ciertos sectores, la ciudadanía aprecia el esfuerzo realizado con este equipamiento y se muestra orgullosa de él tal como se pudo apreciar en las jornadas de puertas abiertas realizadas en su inauguración, aunque según otros, y ante la carencia de equipamientos como los sanitarios y asistenciales, "se deberían jerarquizar las necesidades antes de decidir una inversión pública de tales dimensiones".

\section{VI.2.g. Criterio 7. Colaboración y coordinación interinstitucional.}

Hasta fechas recientes, se ha prestado una limitada atención al estudio de las relaciones entre planeamiento urbanístico, iniciativas culturales y turismo en los conjuntos patrimoniales. Sin embargo, recientes iniciativas impulsadas desde la Administración General del Estado, desde la comunidades autónomas y desde algunos ayuntamientos, evidencian que se está iniciando un cambio de tendencia que está propiciando un mayor encuentro entre estrategias urbanísticas, culturales y turísticas.

En Toledo, como resultado de la firma de colaboración suscrita entre el Ministerio de Economía, la Junta de Comunidades de Castilla-La Mancha, el Ayuntamiento y la Federación Empresarial Toledana (FEDETO), surge el Plan de Excelencia Turística en el año 2000. En la ciudad conquense, el Proyecto Integral de Mejora Urbanística dirigida al Turismo 1994-1999 y el Plan de Dinamización Turística, aprobado en 1998, iniciaron su andadura en un marco de cooperación interadministrativa. Entre las actuaciones de este último, y en relación con el estudio de caso que nos ocupa, se encuentra la adecuación del teatro-auditorio como sala de congresos y la creación y puesta en marcha de la Fundación Cuenca Ciudad de Congresos, un novedoso modelo de gestión turística, fruto del acuerdo entre la Junta de Comunidades, la Diputación Provincial, el Ayuntamiento, la Federación de Asociaciones de Empresarios de Cuenca, la Cámara de Comercio e Industria y la Caja de Ahorros de Castilla-La Mancha. Unos años más tarde se unió la Agrupación Provincial de Empresarios de Hostelería y Turismo de Cuenca. Se cumplió así uno de los objetivos prioritarios del plan: la coordinación y la 
apuesta conjunta tanto de las administraciones públicas como del sector empresarial para el fomento del desarrollo de la economía de Cuenca en materia turística.

A pesar de su denominación, los objetivos y trabajos llevados a cabo por la Fundación no fueron encaminados única y exclusivamente a la potenciación del turismo de reuniones, sino también a la ordenación y promoción de la oferta existente en la ciudad para poder captar un mayor volumen de turistas tanto nacionales como internacionales entendiendo el enorme potencial de la ciudad de Cuenca como destino de turismo cultural. Esta fundación, junto con el Plan de Dinamización Turística de Cuenca fueron los antecedentes de la Fundación Turismo de Cuenca puesta en marcha en 2004, cuyo objetivo principal es la gestión integral del turismo de la ciudad y la provincia (MonDÉJAR et al, 2009).

Si bien en la construcción del teatro-auditorio colaboraron diferentes instituciones, la gestión durante los diez primeros años dependió única y exclusivamente del ayuntamiento. Después pasó a ser gestionado por un patronato en el que estaban incluidos el ayuntamiento de la ciudad y la diputación provincial. Finalmente ha sido, y sigue siéndolo en la actualidad, la Fundación de Cultura "Ciudad de Cuenca" la gestora del auditorio junto con un Patronato al que corresponde el cumplimiento de los fines fundacionales y la administración de los bienes y derechos que integran su patrimonio.

Según la responsable de la Fundación de Cultura "Ciudad de Cuenca", nunca ha habido un problema a nivel institucional; siempre ha existido un acuerdo tácito de que todo lo planificado dentro del marco de lo cultural era para el bien de la ciudad. Sin embargo, la sensación, según la gerente del auditorio, es que discrepancias ideológicas han interferido en la actividad y programación cultural. La Fundación de Cultura Ciudad de Cuenca y el Teatro-Auditorio de Cuenca atraviesan, según el alcalde de la ciudad, una situación "tremendamente delicada" debido a la reducción de las aportaciones recibidas de las instituciones colaboradoras ${ }^{11}$. Al depender de una fundación, el buen funcionamiento del complejo depende más del color político de las instituciones integrantes que de la coyuntura de crisis; la colaboración de instituciones como la Fundación Caja Rural de Cuenca-Globalcaja o el propio Consorcio son imprescindibles para mantener abierto este espacio y gestionarlo adecuadamente.

${ }^{11}$ CLM24.es. 15 de julio de 2013. Fundación Caja Rural-Globalcaja aportará 40.000 euros al Teatro-Auditorio.

Disponible en http://www.clm24.es/articulo/cuenca/fundacion-caja-rural-globalcaja-aportara-40-000-euros-al-teatro-auditorio/20130715132954016400.html

Polígonos. Revista de Geografía, 25 (2013); 19-56 
La colaboración interinstitucional también está presente en el Palacio de Congresos "El Greco" que ha sido financiado mediante un Convenio firmado por la Junta, la Diputación y el Ayuntamiento, siendo este último el encargado de su construcción (a través de su Empresa Municipal de Suelo y Vivienda) y de su gestión (indirecta, mediante concesión).

La construcción y después la explotación del Palacio de Congresos ha sido objeto de debate público durante años. La alternancia de gobiernos municipales de distinto signo político provocó un aumento en el tiempo de ejecución de la obra; en cuanto a su gestión, la privatización planteada en la legislación del Partido Popular chocó frontalmente con la opinión de Izquierda Unida, que apostaba por una gestión pública. A pesar de que en el comienzo de esta legislatura se discutió menos sobre la forma de gestionar el palacio, lo cierto es que el PSOE tenía claro que "la privatización es una buena fórmula porque los riesgos los asume la empresa concesionaria". Fue la empresa de servicios dedicada a la gestión integral de proyectos inmobiliarios y hoteleros: Gestió i Serveis Trade Center S.A. (GIS), gestora de World Trade Center Barcelona, la empresa adjudicataria del concurso convocado por el Ayuntamiento para la explotación y gestión del mismo, con el compromiso de trabajar con empresas locales o de la provincia en sus servicios. Con este proyecto, la empresa catalana consolida su posición como gestor y comercializador en el mercado de Congresos español ${ }^{12}$.

\section{VI.2.h. Criterio 8. Aplicación del principio de la gobernanza.}

La coordinación y la cooperación, tanto vertical como horizontal, es una las principales debilidades del actual estado autonómico español, aunque son muchos los intentos realizados para conseguir un nuevo gobierno del territorio basado en la participación, la cooperación y la coordinación: observatorios de distinto tipo, planes de excelencia y dinamización turística y consorcios, entre otros. Sin embargo, la coordinación no presupone uniformidad de acción, sino coherencia y compatibilidad (FARINós, 2008). Todos ellos han sido puestos en marcha en las dos ciudades analizadas. No obstante, y pese a que los consorcios se crean para asegurar la coordinación de los distintos niveles de la administración y sus inversiones, la falta de coordinación y de colaboración está a la orden del día desde 2011, en ambos casos como consecuencia del distinto color político entre la administración regional y provincial y la municipal. Además, hay quien critica abiertamente la idea de que una mayor participación resulte una panacea

${ }^{12}$ La Tribuna de Toledo.es. 26 de agosto de 2010. Convocado el concurso para adjudicar la explotación del Palacio de Congresos. Disponible en http://www.latribunadetoledo.es/noticia. $\mathrm{cfm} /$ Local/20100826/convocado/concurso/adjudicar/explotacion/palacio/congresos/AA6C0F810079-7A71-66BDCF41462B7FE5 
"per se", ya que en ocasiones los procesos participativos presentan importantes limitaciones porque se conciben más como un fin que como un medio (WASSENHOVEn, 2008; Masson-VINCENT, 2008).

En el caso que nos ocupa, el teatro-auditorio está gestionado por una fundación. Como centro cultural de referencia máxima en la ciudad, dónde tiene cabida todo tipo de agentes sociales, es referente de integración e intervención de la sociedad civil. No obstante, la sociedad civil se ha involucrado poco en estos años, a pesar de las iniciativas puestas en marcha por la Fundación de Cultura "Ciudad de Cuenca" con el propósito de favorecer la vinculación de los aficionados a las artes escénicas y la música: Club Amigos, Amigo Colaborador y Amigo Protector del Teatro Auditorio ${ }^{13}$.

En Toledo el sector público es el único implicado en la intervención; posteriormente y ante la incapacidad de la administración local de afrontar la gestión del edificio, su mantenimiento y programación, se ha contratado un gestor catalán. La ciudadanía, como en Cuenca, tampoco se implicó en la planificación y construcción, aunque a propuesta del alcalde se abrió en las redes sociales un foro de debate para que los ciudadanos plantearan sus sugerencias y dieran sus opiniones con respecto al nombre del palacio de congresos. A través de la red social facebook, «Miradero» $\mathrm{y}$ «El Greco» fueron las opciones que contaron con más adeptos. También se consideraron los informes de la empresa gestora de las instalaciones que aconsejaban que el Palacio tuviera proyección mundial, con un nombre vinculado a la ciudad y que, al mismo tiempo, fuera universal para poder acceder más fácilmente al mercado internacional. Los especialistas en la materia entendieron que era conveniente ligar el nombre del edificio al de «una figura conocida» internacionalmente y «vinculada a la historia y a la cultura de la ciudad». Con estos argumentos, La Junta de Gobierno Local aprobó dar el nombre de Palacio de Congresos de Toledo «El Greco» al nuevo centro congresual construido en el paseo del Miradero. La empresa 'Gestió i Serveis' (GIS) quedó encargada, bajo la supervisión del Ayuntamiento, de elaborar un logotipo que identificara al Palacio de Congresos de Toledo en el mercado del turismo de reuniones ${ }^{14}$.

13 Teatro Auditorio de Cuenca. Disponible en http://www.auditoriodecuenca.es/portal/ lang_es-ES/tabid_12543/default.aspx

${ }^{14}$ La Tribuna de Toledo.es. El PSOE decide llamar "El Greco" al Palacio de Congresos, 3 de abril de 2012. Disponible en http://www.latribunadetoledo.es/noticia/Z895FAC0F-CA4B-127F53AC22D0FC8BB615/20120413/bautizo/sorpresa/impuesto

ABC.es. El Greco dará nombre al Palacio de Congresos de Toledo. Ana Pérez Herrero, 12 de abril de 2012. Disponible en http://www.abc.es/20120412/local-toledo/abci-greco-dara-nombrepalacio-201204121434.html

Polígonos. Revista de Geografía, 25 (2013); 19-56 
Aunque las escalas de los dos cascos históricos no son las mismas, en Toledo el asociacioneimo vecinal está más presente que en Cuenca: "Iniciativa del Toledo Histórico", "La Mezquita", "Asociación de Residentes del Casco Histórico de Toledo" y "La Cornisa" son algunas de las asociaciones de vecinos del Casco Histórico de Toledo. Surgieron de distintos grupos de residentes afectados por la falta de espacios donde aparcar, la reducción de plazas de la ORA para residentes, las molestias del tráfico rodado de taxis o autobuses, la imposibilidad de bajar el pivote retráctil de alguna calle, los ruidos originados por algunos locales de ocio y la falta de servicios públicos o problemas con alguno de ellos. En el caso de Cuenca, es la Asociación de Vecinos del Casco Antiguo la única existente en este espacio urbano, y la que reivindica, desde su creación, un casco vivo, multifuncional y, fundamentalmente, residencial.

\section{VI.2.i. Criterio 9. Avances alcanzados.}

Respecto a los avances alcanzados, las opiniones están divididas. Hay quien piensa en el auditorio -el político- como "centro cultural de referencia en la ciudad", como "ejemplo de intervención de la sociedad civil y de integración". Frente a lo anterior, el técnico opina que "el luchar contra la discriminación nunca ha sido objetivo del teatro-auditorio, "únicamente se perseguía el ofrecer espectáculos de interés para el público, arriesgando alguna vez con propuestas menos lúdicas, una buena puesta en escena o un reparto de famosos televisivos"; los "espectáculos reflexivos o filosóficos resultaban flojos de taquilla".

Hasta hace unos años el teatro-auditorio y su actividad, especialmente la de congresos, servía para justificar la necesidad de un palacio de congresos en una ciudad que pronto estaría comunicada por AVE con Madrid y Valencia. Además, se entendía que aquí era más económico organizarlo y más atractivo por la relación entre el patrimonio natural y urbano de su casco histórico. Actualmente han ganado la partida otras ciudades como Toledo; además, la crisis económica hace impensable el construir ese tipo de equipamiento en los próximos años.

Respecto al Palacio de Congresos de Toledo "El Greco", es difícil llegar a unas conclusiones dado el escaso tiempo que lleva en funcionamiento, pero se entiende que "en un futuro a medio plazo se producirán cambios importantes en el tipo de turismo; ya no será un turismo fundamentalmente cultural, será un turismo de congresos, de profesionales, de la administración, empresas o banca" que dinamizaran ciertos sectores económicos en el casco histórico, fundamentalmente el relacionado con el hostelero. 


\section{DEBATE.}

En Cuenca la construcción del equipamiento sociocultural analizado se abordó con bastante antelación a la redacción y aprobación de un Plan Especial en el casco histórico, ante la necesidad de una instalación de este tipo cuando se produjo el cierre del último teatro-cine de la ciudad. Además, se contaba con un festival internacional -la Semana de Música Religiosa- que necesitaba espacios con mayor aforo. Aunque en esos años se construyeron numerosos equipamientos culturales en toda España, sin duda Cuenca lo tuvo antes por el prestigio de su Semana de Música Religiosa.

En el caso de Toledo la mencionada intervención aparece recogida en el Plan Especial. En este caso, la presencia del Teatro Rojas y de salas como la de la Caja de Ahorros o la de Caja Rural constituían una oferta, aunque limitada, de funciones socioculturales en la ciudad. No obstante, la cercanía a Madrid y la intención de proyectar la imagen de la ciudad más allá de la región, hicieron aconsejable esta edificación.

Con las actuaciones del programa Castilla-la Mancha a Plena Luz en el marco del subprograma Potenciación del Equipamiento Sociocultural, la construcción del teatro-auditorio y del palacio de congresos, la puesta en marcha de nuevos equipamientos socioculturales contemplados en los Planes Especiales, las intervenciones del Plan de Dinamización Turística de Cuenca y del Plan de Excelencia Turística, y la elaboración de la Estrategia Turística de Toledo, se ha revalorizado la imagen simbólica, cultural y turística de la ciudad de las hoces, y potenciado el centro histórico de la ciudad del Tajo como un centro fundamentalmente terciario, situación esta última potenciada por el estatus de capital regional y la proliferación de usos administrativos en edificaciones del centro histórico.

No obstante, sería deseable hacer un seguimiento en el tiempo de la evolución de la actividad cultural del palacio de congresos puesto que apenas lleva un año en funcionamiento. Sería aconsejable continuar con la investigación durante un período de tiempo más dilatado, para poder constatar si, efectivamente, el tiempo todo lo iguala y nuestros ojos se acostumbran al nuevo equipamiento como ocurrió en Cuenca, ciudad en la que después de unos años se han difuminado los conflictos generados por la dudosa integración paisajística en el entorno natural de la hoz del Huécar. En la actualidad, la obra de García de Paredes está totalmente asumida por la sociedad e integrada en el paisaje de la hoz. Pero el tiempo también es necesario para comprobar lo manifestado en el trabajo de campo por los agentes urbanos entrevistados: el papel del palacio de congresos va a ser clave en la potenciación de las actividades culturales en la ciudad y paralelamente, la reactivación de otras funciones, fundamentalmente la hostelera. 
Una vez analizadas todas y cada una de las entrevistas realizadas, es en Cuenca donde la población entrevistada, en general (políticos, técnicos y representantes de la asociación de vecinos), ha valorado más positivamente todos los criterios presentados en las entrevistas. En Toledo, las diferencias entre las respuestas obtenidas son mayores, existiendo unos fuertes contrastes entre las opiniones de los políticos y hosteleros y las de técnicos y vecinos, siendo en general más valorados los criterios en el primer caso. En definitiva, la valoración del Teatro-Auditorio de Cuenca es muy superior al Palacio de Congresos de Toledo "El Greco". Quizá una de las razones de esa valoración sea la necesidad de contar con una intervención como esta en una ciudad en la que había cierta tradición cultural, y en un momento dado se encuentra con que la única instalación existente cierra sus puertas y no existe ya posibilidad de acoger la programación musical y teatral. Pero también porque han transcurrido veinte años desde su inauguración y esta mayor perspectiva temporal ha favorecido la integración del edificio en el paisaje, en las retinas de los ciudadanos. Porque no cabe duda que esta actuación, al menos desde el punto de vista del diseño y de la incardinación en la hoz, pero también desde el punto de vista del presupuesto final al triplicar el inicial o programado, fue también muy polémica en la ciudad.

Fig. 7. Evaluación del Teatro-Auditorio de Cuenca y del Palacio de Congresos de Toledo "El Greco"

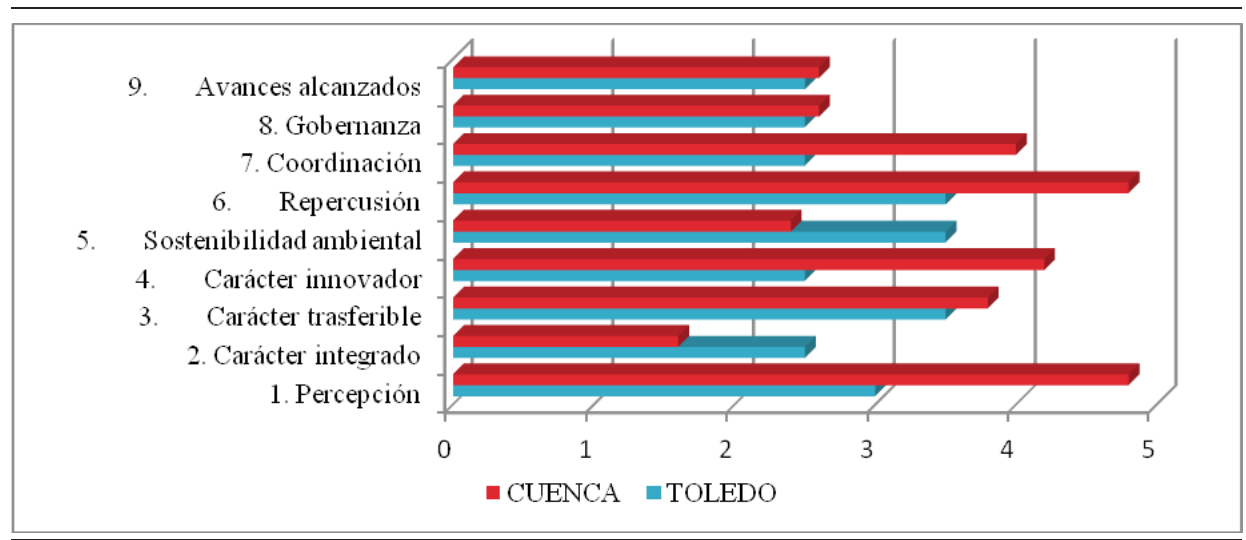

FUENTE: Elaboración propia.

En el caso de Toledo, la valoración ha sido bastante más baja, incluso algunos criterios no han pasado la evaluación, con puntuaciones por debajo del 2,5 sobre 5. Los criterios peor considerados han sido el impacto visual en el paisaje, el presupuesto destinado a la intervención, que se duplicó en respecto al inicial, y la falta de "cooperación interinstitucional" provocada por la existencia de administraciones de distinto signo político. 
En relación con el diseño del edificio y la integración en el paisaje, muchos especialistas consideran que los conjuntos históricos requieren de la presencia de arquitectura contemporánea a partir del respeto y la puesta en valor del entorno existente y de la coherencia de la imagen urbana (Covarrubias, 2009; Vázquez, 2009; De María, 2009, Cerrillos, 2012; Gómez, 2012). A lo largo de su historia las ciudades han sido siempre fieles a su momento histórico y estético, es ahora, con la aparición de los "conceptos de protección" y de los "expertos en patrimonio" cuando el centro de la ciudad "se llena de miedos mientras entre todos la empujamos al precipicio de la falsificación” (CERRILlos, 2012: 12).

\section{PARTE PROPOSITIVA Y CONCLUSIONES.}

Estas ciudades, tras haber realizado un importante esfuerzo financiero en la construcción de nuevos equipamientos socioculturales, están en condiciones de perfilar una estrategia urbana donde el patrimonio cultural y medioambiental sean los pilares para diversificar la oferta y apostar por consolidarse como un destino de calidad, si se refuerza la gestión y se logra una mayor implicación del sector privado. Además, con el fin de conseguir políticas coherentes, debería darse pleno contenido al principio de sostenibilidad; de esta forma se impulsarían medidas con enfoque estratégico.

No obstante, en lugar de partir del turismo cultural como factor impulsor estratégico para el desarrollo urbano, deberíamos plantearnos el supuesto contrario, es decir potenciar una base económica diversificada y competitiva, desarrollando sus recursos turísticos como una función complementaria, susceptible de aportar sinergias al proceso de desarrollo urbano (PRECEDo y Míguez, 2007). Se debería lograr la integración en el marco de una realidad urbana plurifuncional y convertirla en un factor de recuperación de las economías urbanas, intentando conseguir una conexión entre la planificación turística, las políticas económicas, urbanísticas y medioambientales. La planificación turística debería ir mucho más allá de la promoción y de la mejora del equipamiento hostelero (TRoITIÑo, 1995 y 1996). Sin embargo, la presión del turismo también implica efectos negativos a nivel ambiental, social y funcional.

A esto hay que unir la necesidad de una mayor seguridad financiera y claridad competencial de los gobiernos locales, ya que es en esta escala donde más se aprecia la ausencia de coordinación supramunicipal. Por otra parte, la buena gobernanza territorial, además de descansar sobre los principios de coordinación y cooperación, requiere además de una sociedad civil fuerte (RoMERO y FARINós, 2011). Según Troitiño (2006), debería asumirse la singularidad física, simbólica 
y funcional de los destinos patrimoniales y poner en marcha estrategias cualitativas, consensuadas con los diversos agentes sociales, si se quiere evitar la insostenibilidad cultural y turística. Deben promoverse estrategias combinadas "topdown" y "bottom-up", desde arriba y desde abajo, desde instituciones públicas o privadas en las que es fundamental el liderazgo político, y desde la ciudadanía, desde empresas o asociaciones, desde espacios para la participación. Algunos de los criterios esgrimidos por Borja (2005: 3) para orientar las intervenciones en estos espacios consisten en aumentar la oferta cultural, estimular la iniciativa social y potenciar la dimensión participativa de la población en la gestión de las actuaciones y los servicios. Cada uno de estos enfoques tiene sus fortalezas y sus debilidades, de ahí que sea aconsejable pensar en un enfoque híbrido que reúna lo positivo de uno y de otro para poder dar respuestas a los problemas planteados en estos espacios (VIEIRA, 2012).

A pesar del efecto demostrativo que ambas intervenciones pudieran tener en otros espacios urbanos, no va a llevar implícita la construcción de actuaciones de este tipo, al menos en tiempos de crisis como los actuales. Además, y en relación con la falta de recursos financieros, sería conveniente jerarquizar las prioridades porque suelen ser espacios con carencias importantes para la población.

Uno de los grandes retos del siglo XXI es la revitalización funcional de los centros históricos desde una óptica multifuncional, alimentando centralidades como la turística y la cultural. La inclusión de los recintos históricos de Toledo y Cuenca en la Lista del Patrimonio Mundial ofrece una oportunidad de oro para conectar turismo y cultura, así como caminar en el marco de una estrategia de desarrollo turístico sostenible. El equipamiento sociocultural ha desempeñado un importante papel en la recuperación funcional de los Centros Históricos; sin embargo, el resurgir cultural ha tenido un limitado efecto multiplicador en el momento de generar empleo o de crear un comercio especializado relacionado con el mundo del arte y de la cultura. Sin embargo, el futuro comercial del casco antiguo, sin presentarse muy brillante, puede mejorar en relación con la diversificación de la oferta turística y la revalorización cultural y simbólica de este espacio urbano.

En los estudios de caso analizados esa función sociocultural se ha instalado en nuevas edificaciones construidas en las márgenes de los centros históricos, junto a los ríos que marcan el perímetro de estos espacios. Ambas intervenciones han sido realizadas por arquitectos de prestigio, y ambas han sido objeto de fuertes polémicas como consecuencia del impacto, supuestamente negativo, en las imágenes de las cornisas de sus cascos históricos.

No obstante, hay ciertos sectores de la ciudadanía que, como afirma González Galván (1991), consideran positiva la inserción de nueva arquitectura en 
los centros históricos, y aunque debe mostrar el espíritu de la época actual, ha de respetar la tradición sin desdecir a los edificios predecesores y vecinos. Como se expresó en el VII Encuentro Internacional de Revitalización de Centros Históricos celebrado en Méjico en el año 2008, es posible reinterpretar la arquitectura antigua con un lenguaje contemporáneo, las imitaciones historicistas no son admisibles.

Por último, se muestra absolutamente prioritaria la necesidad de proceder a una ordenación de los sectores comerciales y turísticos, con una racionalización y modernización de las estructuras comerciales, y una adecuada gestión y ordenación del turismo en la ciudad para evitar interferencias en las diferentes funciones del recinto amurallado. Medidas y propuestas para reestructurar el comercio y ordenar el turismo ya existen, hace falta que quienes deben llevar a la práctica dichas actuaciones no las demoren por más tiempo (CAMPOS, 1999).

\section{BIBLIOGRAFÍA}

Almarcha, E.; Díez De Baldeón, P.; Peris, D.; SÁnchez, I. (2011): Paisajes de los Conjuntos históricos. Castilla-La Mancha . Ciudad Real. Centro de Estudios de Castilla-La Mancha. Junta de Comunidades de Castilla-La Mancha. 359 p.

Alonso, J.M. (2003): Plan Especial de la Ciudad Alta y sus Hoces. Cuenca, AV Arquitectura Urbanismo SA.

BorJa, J. (2005). Un futuro urbano con un corazón antiguo. Barcelona, España: Revista Bibliográfica de Geografía y Ciencias Sociales

Busquets, J. (2000): Toledo y su futuro. El Plan Especial del Casco Histórico de Toledo. Madrid. Ayuntamiento de Toledo, Caja de Castilla-La Mancha, Empresa Municipal de la Vivienda de Toledo, S.A.

CAmpos, M.L. (1999): “Transformaciones del comercio minorista del centro histórico de Toledo, inducidas por los actuales cambios funcionales", en Comercio, turismo y cambios funcionales en las ciudades españolas Patrimonio de la Humanidad (CAMPESINO, A. J., dir.). Cáceres. Cámara de Comercio e Industria. En línea: http://www.camaracaceres.es/actividades/publicaciones/libros/completos/67/contenidos/toledo.htm

Carrasco, D. Revitalización del casco antiguo de Cuenca. Universidad Carlos III de Madrid, Instituto Pascual Madoz. Máster de Política Territorial y Urbanística. 18 edición, Curso 2007/2008.

Cerrillos, M.L. (2012): "La búsqueda de la modernidad y el derecho a la propia historia de nuestras ciudades" en La arquitectura contemporánea en el centro histórico (HUAMANÍ, M.S., coord.) VIII Encuentro de Gestión de Centros Históricos. Guatemala, 7-10 de noviembre de 2011. Agencia Española de Cooperación 
Internacional para el Desarrollo (AECID). Dirección de Relaciones Culturales y Científicas. Programa P>D Patrimonio para el Desarrollo, 11-18.

Covarrubias, F. (2009): "Los centros históricos y la ciudad actual: instrumentos de ordenamiento, conservación, revitalización y uso" en VII Encuentro Internacional de Revitalización de Centros Históricos "La arquitectura de hoy, entre la ciudad histórica y la actual” (PARIS, J., coord.). AECID; Instituto Nacional de Antropología e Historia (INAH), Universidad Autónoma MetropolitanaAzcapotzalco. Ciudad de México 27, 28 y 29 de octubre de 2008. México D.F. Centro Cultural de España en México. 19-38.

DE la CAlle, M. (2013a): "Los recursos del turismo cultural" en Turismo Cultural (PULIDO, J.I. (coord.); DE LA CALLE, M.; VELASCO, M.). Madrid. Editorial Síntesis, 81-116.

DE la Calle, M. (2013b): "Turismo cultural y destinos turísticos" en Turismo Cultural (PULIDO, J.I. (coord.); DE LA CALLE, M.; VELASCO, M.). Madrid. Editorial Síntesis, 203-234.

DE MARíA, A. (2009): "La arquitectura del presente en el espacio histórico" en VII Encuentro Internacional de Revitalización de Centros Históricos "La arquitectura de hoy, entre la ciudad histórica y la actual” (PARIS, J., coord.). AECID; INAH, Universidad Autónoma Metropolitana-Azcapotzalco. Ciudad de México 27, 28 y 29 de octubre de 2008. México D.F. Centro Cultural de España en México. 145-152.

FARINÓs. J, (2008): “Gobernanza territorial para el desarrollo sostenible: estado de la cuestión y agenda". Boletín de la Asociación de Geógrafos Españoles. n 46, 11-32.

GómEz, F. (2012): "En torno a las intervenciones contemporáneas en la ciudad histórica" en La arquitectura contemporánea en el centro histórico (HUAMANÍ, M.S., coord.). VIII Encuentro de Gestión de Centros Históricos. Guatemala, 7-10 de noviembre de 2011. AECID. Dirección de Relaciones Culturales y Científicas. Programa P>D Patrimonio para el Desarrollo, 93-100.

GonzÁlez, M. (1991): “Importancia de los normativos de ley para la conservación de centros históricos" en Disertaciones, $\mathrm{n}^{\circ} 2$. Aguascalientes: Supremo Tribunal de Justicia, p. 95.

MAsSOn-VinCENT, M. (2008): “Governance and geography explaining the importance of regional planning to citizens, stakeholders in their living space". Boletín de la Asociación de Geógrafos Españoles, n 46, 77-96.

Mondéjar, J.A.; MondéJar, J.; Sevilla, C.; Cordente, M. (2009): “La Fundación Turismo de Cuenca: Un nuevo modelo de gestión pública y privada”. PASOS. Revista de Turismo y Patrimonio Cultural. Universidad de Castilla-La Mancha Vol. 7, $\mathrm{n}^{\mathrm{o}}$ 2, 281-296.

Peris, D. (2006): La modif cación de la ciudad: restauración monumental en Toledo s. $X I X$ y XX. Tesis Doctoral Departamento Construcción y Tecnología Arquitectónica. E.T.S. Arquitectura (UPM)

Precedo, A.; Míguez, A. (2007): "La actividad turística como factor de desarrollo en el sistema español de asentamientos (1997-2002). Boletín de la Asociación de Geógrafos Españoles, $\mathrm{n}^{\circ}$ 45, 191-211 
Romero, J.; FARINÓs, F. (2011): “Redescubriendo la gobernanza más allá del buen gobierno. Democracia como base, desarrollo territorial como resultado". Boletín de la Asociación de Geógrafos Españoles, nº 56, 295-319.

Stake, R. E. (1995). Investigación con estudio de casos. Madrid: Morata, 1995.

Troitiño, M. A. (1995): "El turismo en las ciudades históricas", Polígonos. Revista de Geografia, no 5, 49-65.

Troitiño, M .A. (1996): “Las ciudades españolas Patrimonio de la Humanidad: Problemática y realidad actual”, en: Córdoba. Patrimonio Cultural de la Humanidad. Una aproximación geográfica, Gerencia de Urbanismo, Ayuntamiento de Córdoba, 31-52.

Troitiño, M. A. (1998): “Turismo cultural: Toledo", La Actividad turística española en 1996, AECIT, Madrid, 507-514.

Troitiño Vinuesa, M.A. (2006): Centros Históricos: Nuevos procesos y actividades económicas. Turismo y estrategias de cualificación y dinamización. Plan y Gestión urbanística en la rehabilitación de los centros históricos. FEMP. Cuenca, 14 de noviembre de 2006.

Troitiño VinuesA, M.A. (2000) Renovación Urbana: Dinámicas y Cambios Funcionales. Perspectivas Urbanas / Urban perspectives, $\mathrm{n}^{\circ} 2$. El texto proviene de una conferencia impartida en el Curso de Postgrado "Teorías y formas de intervención urbanística”, Colegio de Arquitectos de Aragón. En línea: www.etsav.upc.es/ urbpersp

VÁzquez, G. (2009): “Construir en lo construido” en VII Encuentro Internacional de Revitalización de Centros Históricos "La arquitectura de hoy, entre la ciudad histórica y la actual” (PARIS, J., coord.) (2009): AECID; INAH, Universidad Autónoma Metropolitana-Azcapotzalco. Ciudad de México 27, 28 y 29 de octubre de 2008. México D.F. Centro Cultural de España en México. 73-88.

VIEIRA, J.G. (2012): “La implementación de políticas públicas”. En línea: http://politicas-ypublicas.blogspot.com.es/2012/03/la-implementacion-de-politicas-publicas.html

Wassenhoven, L. (2008): “Territorial governance, participation, cooperation and partnership: a matter of national cultura? Boletín de la Asociación de Geógrafos Españoles, no 46, 53-76

YIN, R.K. (1994): Case Study Research.Design and Methods. London: SAGE, 1994.

\section{FUENTES}

- ABC.ES. "El Greco dará nombre al Palacio de Congresos de Toledo", 12/04/2012. En línea: http://www.abc.es/20120412/local-toledo/abci-greco-dara-nombre-palacio-201204121434.html

- ABC.ES. "El grupo de 13 Ciudades Patrimonio de la Humanidad celebra su XX cumpleaños", 09/09/2013. En línea: http://www.abc.es/toledo/ciudad/20130909/abci-grupo-ciudades-patrimonio-humanidad-201309091338.html 
- ABC.ES. "Los vecinos colaborarán en un plan de renovación urbana”, 09/11/2010. En línea: http://www.abc.es/20101109/toledo/vecinos-colaboraran-plan-renovacion-20101109.html

- ABC.ES "Nace una nueva asociación de vecinos en el Casco Histórico de Toledo". 15/09/2009. En línea: http://www.abc.es/hemeroteca/historico-15-09-2009/ abc/Toledo/nace-una-nueva-asociacion-de-vecinos-en-el-casco-historico-de-toledo_1024125034160.html

- Auditorio de Cuenca. En línea: http://www.auditoriodecuenca.es/desktopdefault. aspx?tabid $=12574$

- Conexo.net. Diario online de Congresos, Reuniones e Incentivos. "La calidad del Palacio de Congresos "El Greco" de Toledo recibe el reconocimietno de TurEspaña y la FEMP con el SICTED”. 27/02/2014. En línea: http:/www.nexotur.com/conexo/cali$\mathrm{dad} / \mathrm{palacio} /$ congresos/lsquo/grecorsquo/toledo/recibe/reconocimiento/turespantildea/ femp/sicted $/ 65536 /$

- CLM24.ES. "Fundación Caja Rural-Globalcaja aportará 40.000 euros al Teatro-Auditorio". 15/07/2013

- En línea: http://www.clm24.es/articulo/cuenca/fundacion-caja-rural-globalcaja-aportara-40-000-euros-al-teatro-auditorio/20130715132954016400.html

- Diputación de Cuenca. En línea: http://www.dipucuenca.es/imunicipal/pinteres. asp?reg=3105

- El Digitalclm. Castilla-La Mancha. "El Palacio de Congresos, nueva y potente infraestructura en el corazón histórico de Toledo". 01/03/2014. En línea: http://www. eldigitalcastillalamancha.es/el-palacio-de-congresos-nueva-y-potente-infraestructuraen-el-corazon-historico-de-toledo-123003.htm

- El PAís. Archivo. "Presentada la maqueta del auditorio de Cuenca", 28/04/1985. En línea: http://elpais.com/diario/1985/04/28/cultura/483487212_850215.html

- El PAís. Archivo. "La reina Sofia inaugura el nuevo teatro auditorio”, 08/04/1994. En línea: http://elpais.com/diario/1994/04/08/cultura/765756009_850215.html

- El PAís. Guía del ocio. En línea: http://www.guiadelocio.com/cuenca/arte/cuenca/ teatro-auditorio-de-cuenca

- Engawa. "Nuevo palacio de congresos en Toledo", 2013. En línea: http://www.engawa.es/index.php?/project/16--nuevo-palacio-de-congresos-en-toledo/

- Gestió i Serveis Trade Center SA (2012): "Palacio de Congresos de Toledo". En línea: http://www.pctoledo.es/es/palacio.html

- hoyesarte.com. "La Semana de Música Religiosa de Cuenca, con El Greco" 18/02/2014. En línea: http://www.hoyesarte.com/evento/2014/04/el-greco-estara-presente-en-la-semana-de-musica-religiosa-de-cuenca/

- LA RED. “Todo sobre las artes escénicas”. En línea: http://www.redescena.net/lared/ quienes_somos/index.php\#faq1 
- La Tribuna de Toledo. "El comercio minorista desciende un 20,7 \% desde que empezó la crisis", 04/08/2013. En línea: http://www.latribunadetoledo.es/noticia/ZB694F8050E8D-2210-71AB1BE2BC7FB4E0/20130804/comercio/minorista/desciende/207/ empezo/crisis

- La tribuna de toledo.es. "Convocado el concurso para adjudicar la explotación del Palacio de Congresos”, 26/08/2010. En línea: ttp://www.latribunadetoledo.es/noticia. cfm/Local/20100826/convocado/concurso/adjudicar/explotacion/palacio/congresos/ AA6C0F81-0079-7A71-66BDCF41462B7FE5

- la tribuna de toledo.es. "El PSOE decide llamar "El Greco" al Palacio de Congresos", 03/04/2012. En línea: http://www.latribunadetoledo.es/noticia/Z895FAC0FCA4B-127F-53AC22D0FC8BB615/20120413/bautizo/sorpresa/impuesto

- Teatro Auditorio de Cuenca. En línea: http://www.auditoriodecuenca.es/portal/ lang_es-ES/tabid_12543/default.aspx

- UrbanScraper Arquitectura+Urbanismo+Ingeniería. Futuro Palacio de Congresos de Toledo. Moneo (Spain). Publicado por FOLK en 30.4.07. En línea: http://www. urbanscraper.com/2007/04/futuro-palacio-de-congresos-de-toledo.html

- Vida y estilo. Terra. es. "Rafael Moneo añade un "Greco" a su colección de edificios", 18/12/2012. En línea: http://vidayestilo.terra.es/casa/rafel-moneo-anade-ungreco-a-su-coleccion-de-edificios,8b4392d3dc6ab310VgnCLD2000000dc6eb0aRC RD.html 